\title{
Long-Chain Polyunsaturated Fatty Acids and Their Metabolites Regulate Inflammation in Age-Related Macular Degeneration
}

\author{
Jiangbo Ren $\mathbb{D}^{1,2, *}$, Anli Ren ${ }^{1,2, *}$, Xizhi Deng², Zhengrong Huang', Ziyu Jiang', Zhi Li', Yan Gong $\mathbb{D}^{1,3}$ \\ 'Department of Biological Repositories, Zhongnan Hospital of Wuhan University, Wuhan, Hubei, People's Republic of China; ${ }^{2}$ Department of \\ Ophthalmology, Zhongnan Hospital of Wuhan University, Wuhan, Hubei, People's Republic of China; ${ }^{3}$ Human Genetics Resource Preservation Center \\ of Wuhan University, Wuhan University, Wuhan, Hubei, People's Republic of China \\ *These authors contributed equally to this work \\ Correspondence: Yan Gong; Zhi Li, Tel +86 27 678I I46I; +86 27 678I 2622, Fax +86 27 678I I47I; +86 27 678I 3I33, Email yan.gong@whu.edu.cn; \\ I 103945483@qq.com
}

\begin{abstract}
Age-related macular degeneration (AMD) is a blinding eye disease, whose incidence strongly increases with ages. The etiology of AMD is complex, including aging, abnormal lipid metabolism, chronic inflammation and oxidative stress. Long-chain polyunsaturated fatty acids (LCPUFA) are essential for ocular structures and functions. This review summarizes the regulatory effects of LCPUFA on inflammation in AMD. LCPUFA are related to aging, autophagy and chronic inflammation. They are metabolized to pro- and anti-inflammatory metabolites by various enzymes. These metabolites stimulate inflammation in response to oxidative stress, causing innate and acquired immune responses. This review also discusses the possible clinical applications, which provided novel targets for the prevention and treatment of AMD and other age-related diseases.
\end{abstract}

Keywords: inflammation, long-chain polyunsaturated fatty acids, age-related macular degeneration

\section{Introduction}

Age-related macular degeneration (AMD) is a disease that damages the macular region of the retina and leads to progressive loss of central vision, which is the leading cause of blindness in the elderly population. ${ }^{1}$ The overall prevalence in Europe was $16.2 \%$ for AMD, and the number of global population with AMD will increase to 288 million by $2040{ }^{2,3}$ AMD is not simply a "macular" disease, but involves the entire retina. ${ }^{4}$ With aging, retinal pigment epithelium (RPE) cells lose the phagocytic and digestive ability at the outer membrane of the optic disc. The residual bodies of the disc membrane remain and deposit on Bruch's membrane, forming drusen and leading to macular degeneration. ${ }^{5}$ Upon Bruch's membrane rupture, choroidal capillaries migrate through the ruptured Bruch's membrane into the RPE and subcutaneous space of retinal nerve, forming choroidal neovascularization (CNV, Figure 1). ${ }^{6}$ Dry AMD, also named non-neovascular, non-exudative or atrophic AMD, is characterized by the development of drusen, ${ }^{7}$ while wet AMD, also known as neovascular or exudative AMD, is characterized by CNV. ${ }^{8}$

It is well recognized that AMD is a multifactorial disease, ${ }^{9,10}$ including genetic predisposition, ${ }^{11}$ oxidative stress, ${ }^{12,13}$ neovascularization, ${ }^{14,15}$ inflammatory responses ${ }^{16}$ and remodeling processes of the retinal extracellular matrix. ${ }^{17}$ Rozing et al proposed that the essence of AMD was a series of damages involved in aging and the consequently activated host immune responses to damages. ${ }^{18}$ Low-grade inflammation is associated with many age-related complications including AMD and neurodegeneration. ${ }^{19}$ Controlling low-grade inflammation can prevent or reduce age-related functional decline. ${ }^{20}$ Pujol-Lereis et al stated that AMD resulted from three interrelated pathological processes, including inflammation, autophagy dysfunction and chronic oxidative stress, which led to RPE degeneration, ultimately photoreceptor cell death and vision loss. ${ }^{21}$ Under oxidative stress, the drusen are formed in the retina, activating the complement system 


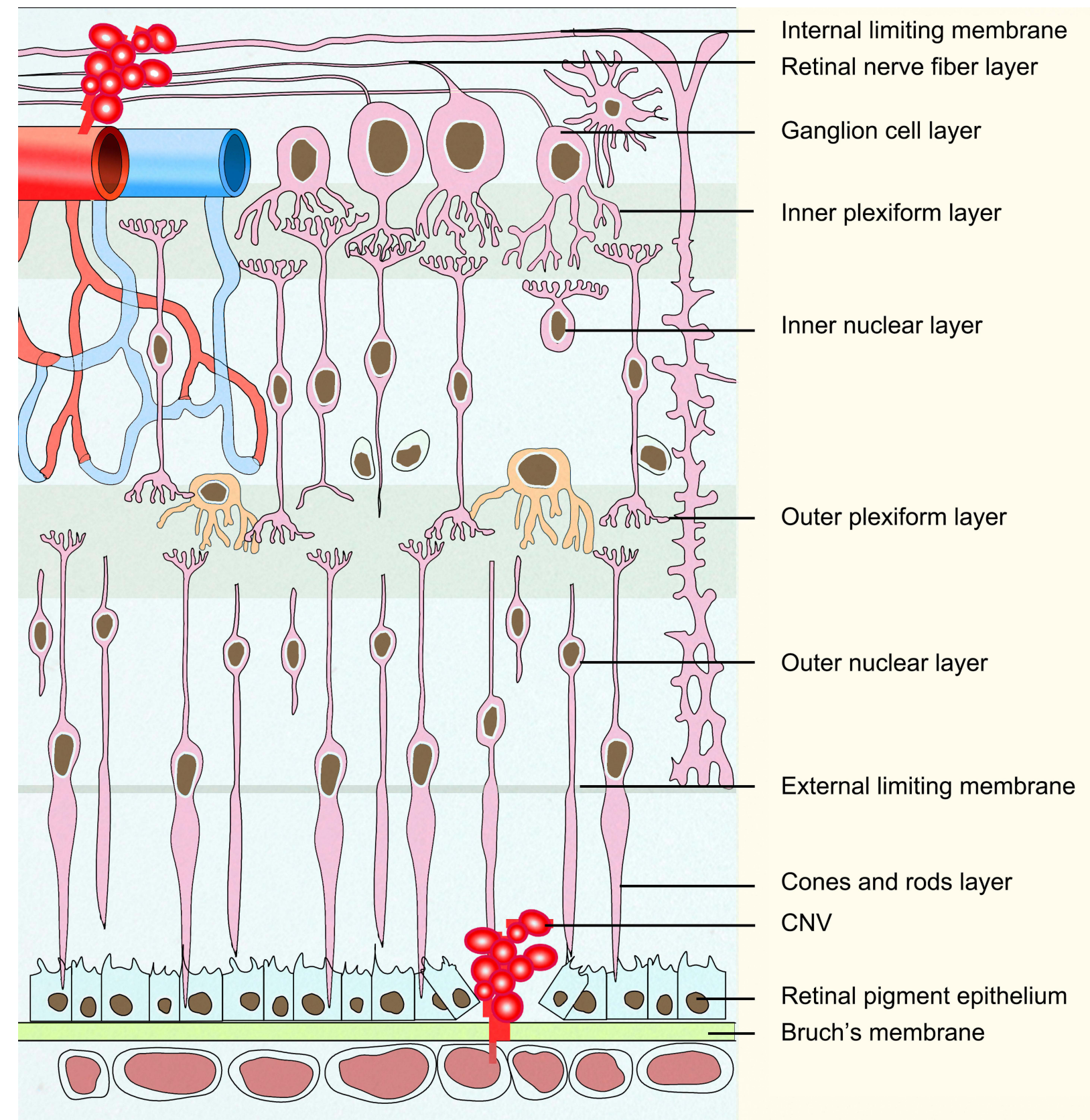

Figure I Composition of the retina and ocular neovascularization. Retinal vessels grow through the retinal nerve epithelium to form retinal neovascularization. The choriocapillaris enter under the RPE through the ruptured Bruch's membrane to form CNV.

to trigger chronic inflammation, and subsequently activate immune cells, such as macrophages. ${ }^{22}$ Invasive immune cells facilitate pathology in the retina, resulting in impairment of photoreceptor cells and Bruch's membrane integrity. ${ }^{23}$

Although the progressive course of AMD is increasingly known, current medical treatments are still limited. ${ }^{24-28}$ Intravitreal injection of anti-vascular endothelial growth factor (VEGF) is currently the most widely used therapy, ${ }^{29,30}$ which still have many disadvantages, such as the loss of visual acuity in long-term treatment, ${ }^{31}$ the potential increase in macular atrophy after long-term usage, ${ }^{32}$ increased risk of complications, ${ }^{33}$ damage to ganglion cells and interfere with RPE function. ${ }^{34,35}$

Eye is one of the organs with high lipid content. ${ }^{36}$ Defects in essential fatty acid metabolism arise in many age-related diseases, such as obesity, type 2 diabetes, hypertension, atherosclerosis, coronary heart disease, immune dysfunction, and cancer. ${ }^{37-39}$ As an important component of retina, the metabolism of long-chain polyunsaturated fatty acids (LCUFCA) is 
closely related to the function of retina. ${ }^{40}$ In recent years, the roles of inflammation and lipid metabolism in retinal diseases have been highlighted. ${ }^{41-43}$ This review mainly focused on the regulation of inflammation by LCPUFA metabolism to facilitate drug development and clinical research.

\section{LCPUFA and AMD}

The retina is one of the tissues with the highest lipid content in the human body. ${ }^{44}$ The rod outer segment of photoreceptor cells consists of a light-sensitive disc containing proteins and lipids including phospholipids (90-95\% of total lipids) and cholesterol (4-6\%). ${ }^{45}$ Among retinal phospholipids, LCPUFA account for approximately $45 \%$ of total phospholipids, saturated fatty acids account for approximately $37 \%$, and monounsaturated fatty acids account for approximately $10 \%{ }^{45}$ The retinas of healthy older adults contain $16.7 \% \omega-6$ LCPUFA and $16.6 \% \omega-3$ LCPUFA. ${ }^{46}$ High concentration of LCPUFA maintains proper fluidity of cell membrane, which is the premise of effective visual transduction and essential to the function of retina. ${ }^{47}$ Genomic analysis shows that variations in lipid metabolism pathways are important contributors to early and late AMD, ${ }^{48} \omega-3$ and $\omega-6$ LCPUFA, as well as their metabolites, are associated with AMD pathogenesis and prognosis. ${ }^{49}$ Omega-3 LCPUFA include docosahexaenoic acid (DHA) and eicosapentaenoic acid (EPA), ${ }^{50}$ while $\omega-6$ LCPUFA include arachidonic acid (AA) and linoleic acid (LA). ${ }^{51}$ The major $\omega-3$ LCPUFA, DHA, comprises $\sim 20 \%$ of retinal weight, ${ }^{52}$ and the major $\omega-6$ LCPUFA, AA, comprises $\sim 10 \%$ of retinal weight. ${ }^{53}$

Omega-3 and $\omega-6$ LCPUFA cannot be synthesized by human body itself, which must be obtained from diet. ${ }^{54}$ The ratio of AA to DHA and EPA can be changed by oral administration of DHA and EPA. ${ }^{55}$ High LA intake is associated with $49 \%$ increases in the risks of AMD, while high DHA intake is associated with $30 \%$ decreases. ${ }^{56}$ Most nutrition guidelines recommend increased intake of food-based EPA, DHA and their precursors (250-1000 mg/day) to reduce the prevalence of AMD. ${ }^{49}$ Many clinical studies show that the high intake of food-based $\omega-3$ LCPUFA (100-800 mg DHA + 30-60 mg EPA/day) is associated with lower AMD incidence rate and less development. ${ }^{57-60}$

A large cohort study, which involved 38,022 Americans, showed that the incidence rate of AMD in population with higher plasma concentration of $\omega-3$ LCPUFA was $42 \%$ lower than that in patients with lower levels. ${ }^{60}$ The age-related eye disease study (AREDS) suggests that bilateral drusen of those with higher intake of $\omega-3$ LCPUFA are $30 \%$ less likely to develop into geographic atrophy (GA) or CNV. ${ }^{61}$ A prospective control study based on 75,889 females and 38,961 males in the United States indicated that higher intakes of EPA and DHA prevented or delayed the occurrence of visually significant intermediate AMD. ${ }^{7}$ Similar results were obtained in both European and Asian countries. ${ }^{62-65}$

However, AREDS2 reported conflicting results. Omega-3 LCPUFA supplementation (350 mg DHA + $650 \mathrm{mg}$ EPA/ day) does not benefit patients with the lowest fish intake. ${ }^{66}$ These results suggested that a minimum concentration of $\omega-3$ LCPUFA may be required to maintain retinal stability, and above this threshold, supplement of $\omega-3$ LCPUFA may not increase benefits. ${ }^{67}$ Nutritional AMD Treatment-2 (NAT-2), a clinical trial on oral supplementation of $\omega-3$ LCPUFA (840 $\mathrm{mg}$ DHA $+270 \mathrm{mg}$ EPA/day) in 263 patients with early lesions of AMD, indicated no significant difference in visual acuity, drusen progression and CNV incidence after oral supplementation. However, the risk of CNV occurrence in individuals with high levels of erythrocyte membrane EPA+DHA within 3 years was reduced by $68 \% .{ }^{68}$ One reason for this discrepancy is the inability to measure retinal $\omega$-3 LCPUFA content directly. ${ }^{69}$ Acar et al developed a more robust prediction model of retinal $\omega-3$ LCPUFA content in AMD based on seven plasma cholesteryl esters, rather than the use of red blood cells or total plasma. ${ }^{69}$ The blood and retinal levels of $\omega-3$ and $\omega-6$ LCPUFA and their relationship with AMD may also depend on genetic polymorphism. ${ }^{70}$ Interestingly, previous studies also suggested that the protective effects of $\omega-3$ LCPUFA on retinal neovascularization may be based on its interaction with AA. ${ }^{71,72}$ The protective and therapeutical effects of LCPUFA on AMD are still to be investigated.

\section{Inflammation and AMD}

Inflammation involves a series of processes aimed at ultimately clearing pathogens and repairing damaged tissues, and is an important pathogenesis in AMD. Local inflammation causes edema of macular and retinal, degeneration of RPE and photoreceptor outer segments (POS), destruction of Bruch's membrane and the development of CNV. ${ }^{73} \mathrm{RPE}$ cells help to maintain the health of the retina, including the formation of outer blood-retinal barrier, the phagocytosis of POS, 
screening of growth factor screening and scavenging of damaged reactive oxygen species (ROS). ${ }^{74}$ When the barrier is disrupted, the inflammatory responses are activated in the retina, resulting in the release of pattern recognition receptors (PRRs) and inflammasomes, and the activation of complement system, immune cells and cytokines. ${ }^{22}$ RPE and immune cells produce cytokines and chemokines leading to the inflammatory cascades. ${ }^{75}$ These cytokines include interleukin (IL)- $4 / 5 / 6 / 8 / 10 / 13 / 17$, interferon- $\beta / \gamma$, transforming growth factor (TGF)- $\alpha$, monocyte chemoattractant protein-1 (MCP-1), and VEGF. ${ }^{76}$ Many studies demonstrated that the levels of pro-inflammatory factor such as IL-6, IL-8, MCP-1 and VEGF were elevated in intraocular fluid of patients with dry and wet AMD. ${ }^{77,78}$ Inflammatory cytokines also enhance VEGF secretion, which initiates and causes pathological CNV and retinal neovascularization in AMD. ${ }^{79,80}$ When the long-term struggle between pro- and anti-inflammatory responses ultimately loses balance, AMD occurs. ${ }^{81}$ In addition, innate immune cells such as macrophages, microglias, dendritic cells, and neutrophils are closely associated with the development of AMD ${ }^{82-85}$ but whether adaptive immunity has a role in AMD is highly debated. ${ }^{86}$

Inflammatory responses contribute to both dry and wet AMD through different mechanisms. ${ }^{82} \mathrm{CNV}$ is closely linked to inflammatory cytokines, complement system activation, and promotion. ${ }^{87}$ Animal and in vitro experiments showed that complement activation and membrane attack complex (MAC) formation induced CNV and that inhibiting C3a, C5a and MAC effectively inhibited CNV. ${ }^{88,89}$ After anti-VEGF treatment, the elevated concentrations of interferon gammainducible protein-10 (IP-10), IL-6, IL-8, C-X-C motif chemokine-12 (CXCL12), CXCL13, IL-10 and MCP-1 in the aqueous humor of AMD patients were decreased, ${ }^{90,91}$ while Sato et al found IL-6 and IP-10 were considerably increased. ${ }^{92}$

Complement components, the important component of drusen, and inflammasomes are involved in the inflammatory responses in AMD. ${ }^{93-95}$ The activated complement component $\mathrm{C} 3 \mathrm{a}$ was higher in both the blood and drusen of patients with dry AMD, and the inhibitors of complement such as complement factor $\mathrm{H}(\mathrm{CFH}), \mathrm{CD} 59$ and CD46 were reduced, implicating a hyperactive complement system in AMD. ${ }^{96-98}$ Upon oxidative stress, lysosomal destabilization and P2X7 receptor activation, inflammasomes can be activated by the nucleotide-binding and oligomerization domain-like receptor (NLR) family containing 1 (NLRP1), NLRP3, NLR-family CARD-containing protein 4, absent-in-melanoma 2 or pyrin, ultimately cause pyroptosis. ${ }^{99}$ Immunohistochemistry revealed the presence of the NLRP3 inflammasomes in the lesion area of the eye in both GA and CNV. ${ }^{100}$ In an acute model of AMD, inflammasome activation and increased IL-18 prevent CNV, but lead to RPE cell loss during a chronic model of $\mathrm{GA},{ }^{101}$ which may be related to the degree and duration of inflammation.

Taken together, pathological processes of AMD are delicately regulated by various immune-mediated inflammatory events, including oxidative stress, mitochondrial dysfunction, autophagy, endoplasmic reticulum stress and cellular senescence, which are associated and interacted with each other. ${ }^{102,103}$

\section{Regulation of Inflammation by LCPUFA in AMD}

The metabolites of LCPUFA, metabolized by enzymatic or non-enzymatic pathways, regulate inflammatory processes and have complex effects on AMD. For instance, $\omega$-3 LCPUFA downregulate insulin-like growth factor-1, attenuate the activation of nuclear factor- $\mathrm{KB}(\mathrm{NF}-\mathrm{\kappa B})$, IL- $\beta$, VEGF and tumor necrosis factor- $\alpha$ (TNF- $\alpha$ ), and suppress inflammation, ${ }^{104-106}$ in part through the sphingomyelinase pathway. ${ }^{107}$ Currently, there are many drugs, such as saffron and fenofibrate, targeting lipid metabolism and inflammatory process at different periods of development (Table 1). Several lipid metabolites are being investigated as therapeutical products as well (Table 2).

\section{Effects of LCPUFA Oxidative Metabolites on Inflammation in AMD}

LCPUFA participate in processes that cause or resolve inflammation through oxidized lipids. ${ }^{107}$ Phospholipase A2 catalyzes the hydrolysis of cell membrane lipids, releasing them for further metabolism and signaling. ${ }^{129}$ Membranebound $\omega-3$ and $\omega-6$ LCPUFA are oxidized by three pathways, the cyclooxygenases (COXs), lipoxygenases (LOXs) and cytochrome P450 oxidases (CYPs). ${ }^{130}$ The metabolites of $\omega-6$ LCPUFA through COX are prostaglandin (PG) E2 and thromboxane, while the metabolites of $\omega-3$ LCPUFA through COX are PGE3 and resolvins (Figure 2). PGE2 stimulates pathological retinal neovascularization. ${ }^{131}$ PGE3 antagonizes PGE2, inhibiting endothelial tubule formation via reducing angiopoietin 2 and matrix metalloproteinase (MMP) 9 production. ${ }^{125}$ Resolvins have anti-inflammatory properties, ${ }^{128}$ 
Table I Drugs Targeting Lipid Metabolism and Inflammatory Processes

\begin{tabular}{|c|c|c|c|}
\hline Medicine & Period & Target & Mechanism \\
\hline $\begin{array}{l}\text { NAC, }{ }^{108} \text { saffron, }{ }^{109} \text { vitamin C, E, } \\
\text { zinc, }^{110} \text { resveratrol }{ }^{111}\end{array}$ & Clinical experiment & SOD, GPx, GSH activator & $\begin{array}{l}\text { Reduce ROS levels, stimulate } \\
\text { autophagy }{ }^{1 / 2}\end{array}$ \\
\hline Troglitazone, rosiglitazone $\mathrm{I}^{1 / 3}$ & Clinical experiment & PPAR $\gamma$ activator & Anti-inflammatory, inhibit $\mathrm{CNV}^{1 / 4}$ \\
\hline Celecoxib $^{115}$ & Clinical experiment & COX-2 inhibitor & Anti-inflammatory, inhibit CNV \\
\hline NS-398 116 & Cell experiment & & \\
\hline Fenofibrate $e^{117}$ & Animal experiment & PPAR $\alpha$, CYP2C activator & Anti-inflammatory, inhibit CNV \\
\hline $\mathrm{SH}-\mathrm{II} 037^{118,119}$ & Clinical experiment & sEH inhibitor & Anti-inflammatory, inhibit CNV \\
\hline SRI001 120,121 & Cell experiment & ROR $\alpha$ inhibitor ${ }^{122}$ & $\begin{array}{l}\text { Control transcription of lipid } \\
\text { metabolism, reduce inflammation }\end{array}$ \\
\hline MRZ-99030115 & Clinical experiment & Amyloid- $\beta$ inhibitor & Reduce drusen formation \\
\hline Avacincaptad pegol ${ }^{123}$ & Clinical experiment & C5 inhibitor & Inhibit complement activation \\
\hline
\end{tabular}

Abbreviations: NAC, acetyl-L-cysteine; SOD, superoxide dismutase; GPx, glutathione peroxidase; GSH, glutathione reductase; ROR, retinoic acid receptor-related orphan receptor.

Table 2 Products of Lipase Metabolism with Anti-Inflammatory Effects

\begin{tabular}{|c|c|c|}
\hline Metabolism & Enzyme & Mechanism \\
\hline $4-\mathrm{HDHA}^{124}$ & COX, CYP & Activate PPAR $\gamma$ \\
\hline PEG3 $3^{125}$ & $\operatorname{cox}$ & Antagonize PEG2 \\
\hline Neuroprotectin DI ${ }^{126}$ & LOX & Attenuate $\mathrm{CNV}$ formation and inflammation \\
\hline Maresins $^{127}$ & COX, LOX & Anti-inflammatory and pro-resolving \\
\hline Resolvins $^{128}$ & $\operatorname{cox}$ & Activate chemokine receptor 23 and antagonize LTB4R \\
\hline
\end{tabular}

Abbreviations: 4-HDHA, 4-hydroxydocosahexaenoic acid; PEG, polyethylene glycol; LTB4R, leukotriene B4 receptor.

activating chemokine receptor 23 and antagonizing leukotriene B4 (LTB4) receptor, which mediates the pro-inflammatory effects of LTB4. ${ }^{132}$

Aspirin and other nonsteroidal anti-inflammatory drugs are the most commonly used COX inhibitors in the clinic, and COX inhibition does not affect proliferative retinopathy, possibly due to the concomitant reduction in the intraocular antiinflammatory $\omega-3$ and pro-inflammatory $\omega-6$ LCPUFA mediators. ${ }^{133}$ However, the COX-2-selective antagonist NS-398 reduced VEGF and TGF- $\beta$ secretion, and attenuated experimental CNV lesions and retinal fibrosis in vivo. ${ }^{116}$

LOX is a lipid peroxidase devoid of heme containing iron that catalyzes the dioxygenesis of LCPUFA to form various bioactive lipids. ${ }^{134}$ 5-LOX and 12/15-LOX were reported to regulate chronic inflammation and oxidative stress. ${ }^{135}$ Previous studies showed that 5-LOX and its metabolite 4-hydroxydocosahexaenoic acid mediated the protective effects of $\omega-3$ LCPUFA against AMD. ${ }^{124}$ The metabolites of $\omega-3$ LCPUFA through LOX pathways contained anti-inflammatory factors, but also pro-inflammatory catabolism such as D-series resolvins, neuroprotectins, and maresins. ${ }^{107}$ Resolvins were powerful regulators of innate immune cells during inflammation and reduced ROS. ${ }^{127}$ Neuroprotectin D1 attenuated CNV and significantly inhibited ROS-mediated damage, apoptosis, and inflammation, resulting in photoreceptor cell integrity. ${ }^{126}$ Maresins are synthesized by macrophages and potent anti-inflammatory mediators. ${ }^{127}$

The roles of LCPUFA metabolites from CYPs are currently attracting increasing attentions. AA is metabolized to hydroxyeicosatetraenoic acids and epoxyeicosatrienoic acids (EETs) by CYPs, while EPA and DHA are metabolized to epoxyeicosatetraenoic acids (EEQs) and epoxyeicosapentaenoic acids (EDPs). ${ }^{136}$ These products are all further metabolized into substances with low activity by soluble epoxide hydrolase (sEH). ${ }^{137}$ Both the $\omega-6$ LCPUFA metabolite 14,15-EET and the $\omega-3$ LCPUFA metabolite 19,20-EDP of CYP2C promote ocular neovascularization. ${ }^{138}$ Inhibition of CYP2C activity increased the protective effects of dietary $\omega-3$ LCPUFA on pathological retinal and choroidal angiogenesis. ${ }^{139}$ However, Hasegawa et al found the inhibitory effects of $\omega-3$ LCPUFA on CNV were impaired by the metabolic degradation of EDP and EEQ. ${ }^{140}$ Other studies showed that 11,12-EET and 19,20-EDP reduced TNF $\alpha$-induced NF- $\kappa \mathrm{B}$ activity and the expression of IL-1 $\beta$, IL-6 and leukocyte adhesion protein VCAM1 in human retinal 


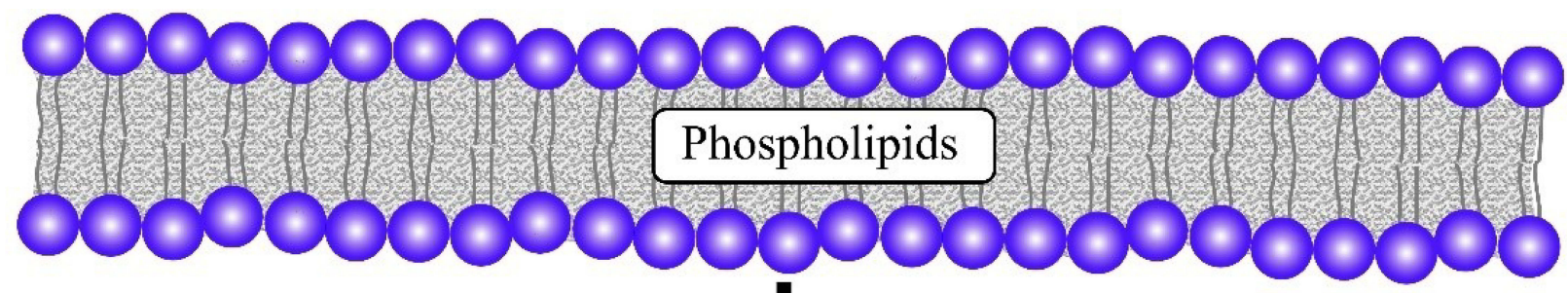

Phospholipase A2

\section{Free arachidonic acid}

$\omega-6$ LCPUFAs

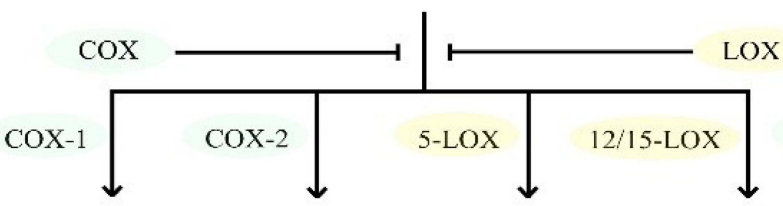

PGE2

TXA2
Pro-Angiogenesis

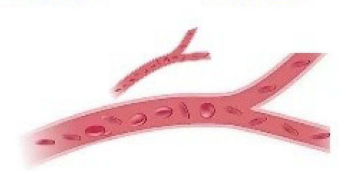

HETES

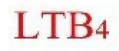

Pro-Inflammation

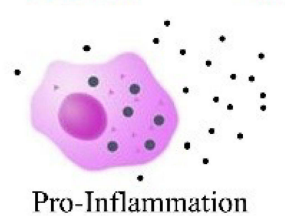

HETEs Resolvins $\omega-3$ LCPUFAs

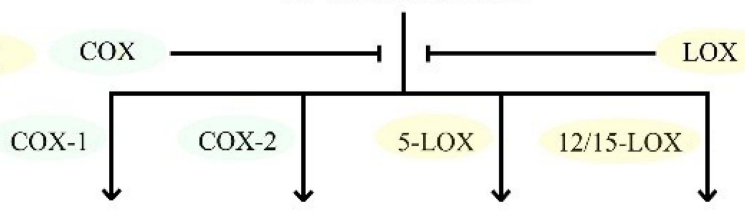

PGE3 Resolvins

Resolvins

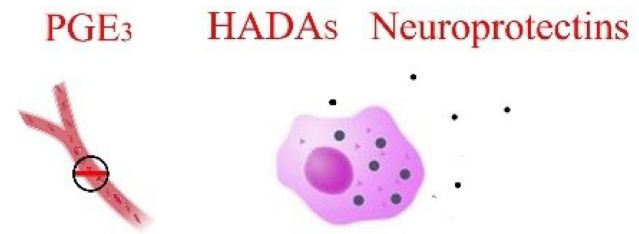

Anti-Angiogenesis Anti-Inflammation

Figure 2 Schematic of the COX and LOX pathways metabolizing $\omega-6$ and $\omega-3$ LCPUFA. The metabolites derived from $\omega-6$ LCPUFA are pro-inflammatory and proangiogenic, whereas those derived from $\omega-3$ LCPUFA are anti-inflammatory and anti-angiogenic.

microvascular endothelial and Müller cells. ${ }^{141,142}$ Fenofibrate, a peroxisome proliferator activated receptor $\alpha$ agonist and CYP2C antagonist, ${ }^{117}$ was reported to suppress CYP2C activity and add to the protective effects of $\omega-3$ LCPUFA on the retina in both in vivo AMD mouse model and ex vivo angiogenesis, via downregulating the levels of 19,20-EDP. ${ }^{143}$

Peroxidation products of non-enzymatic pathways can also modulate cytokines. Acid-N-retinoic ethanolamine (A2E) can increase the secretion of inflammatory cytokines and chemokine such as IL-6, MCP-1, CXCL8, TNF and VEGF both in vitro and in vivo. ${ }^{22,23,144}$

\section{LCPUFA Peroxidation and Its Effects on Inflammation in AMD}

Lipid peroxidation is an important component of oxidative stress, which causes ROS-induced cell damage and has been linked to many degenerative diseases. ${ }^{145,146}$ The unsaturated structure of LCPUFA is particularly susceptible to oxidative degradation by lipid peroxidation, generating harmful end products that lead to irreversible alterations in cellular components. ${ }^{147}$ ROS and oxidized lipoproteins cause cellular stress, resulting in innate immune responses through the activation of cell-associated and soluble PRRs. ${ }^{148}$ Kim et al applied a rat model with subretinal injection of human lipid hydroperoxide to mimic the pathogenesis of AMD. ${ }^{149}$ Pro-inflammatory factors, including TNF- $\alpha$, IL-1 $\beta$ and IL- 6 , were upregulated both in the retinal and choroidal tissues, followed by the increase of LCPUFA peroxidation products such as 4-hydroxynonenal (4-HNE), lipofuscin and carboxy ethyl pyrrole (CEP), ${ }^{149}$ which bind to cellular proteins to form advanced lipoxidation end products (ALEs). ${ }^{150}$

Oxidized lipoproteins were taken up through the CD36 receptor, together with the lipid peroxidation end product 4HNE (Figure 3), activate the NLRP3 inflammasomes in RPE cells through the activation of toll-like receptors (TLRs), receptor for advanced glycation end products (RAGEs), and NF-kB. ${ }^{151-153}$ When inflammasomes were initiated, RPE 


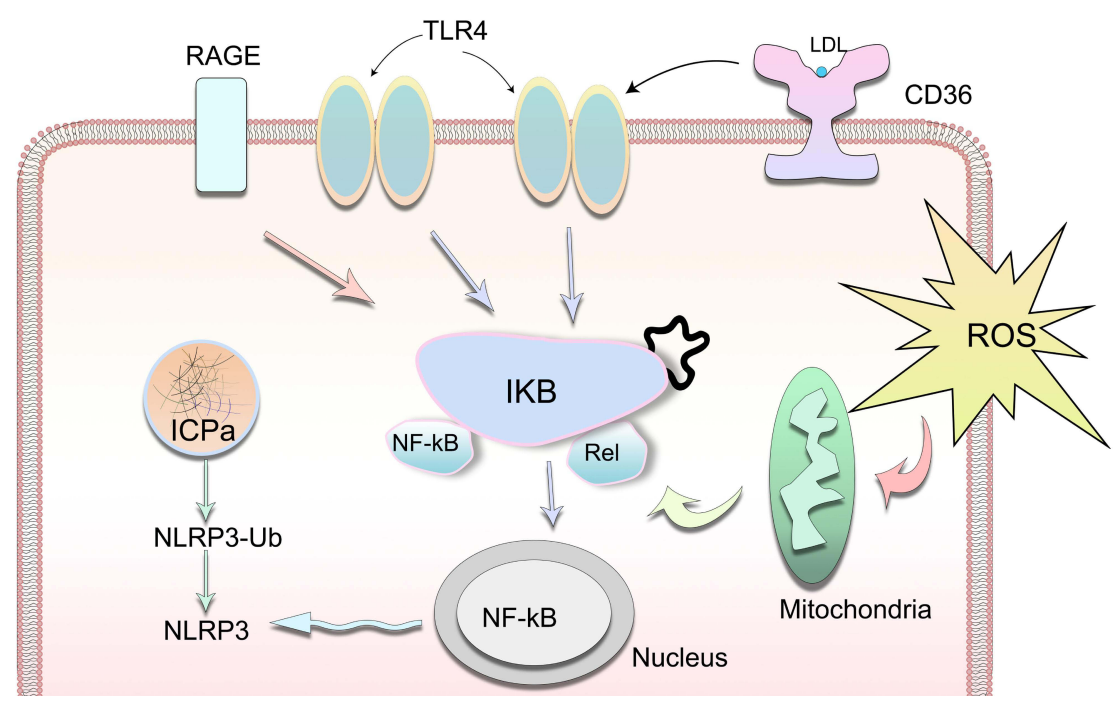

Figure 3 Oxidative stress results in innate immunity responses through the activation of TLRs, CD36, RAGEs, NF- $\mathrm{B} B$ and NLRP3 in stressed RPE cells.

cells died of photo oxidative damage and pyroptosis. ${ }^{154}$ DHA was reported to alter the composition of lipid rafts via entering the cell membrane, leading to the efflux of inflammatory receptors such as TLR2 and TLR4 from lipid rafts, and inhibiting their activation. ${ }^{100}$ 4-HNE can also inhibit the production of IL-8 and MCP-1, ${ }^{155}$ induce epidermal growth factor receptor activation to prevent oxidative stress damage at lower concentrations, but induces p53-mediated apoptosis in RPE cells at a higher concentration. ${ }^{156,157}$

Lipofuscin is the main source of ROS, and its main component is A2E, which is a by-product of vitamin A metabolism and lipid peroxidation. ${ }^{158}$ The process of lipid peroxidation cleaves A2E, activating complement $\mathrm{C} 2$ and $\mathrm{C} 3$, releasing cytotoxic carbonyl species and aggravating RPE damage. ${ }^{144,159}$ On one hand, these peroxidation products can activate the alternative lectin pathways of complement and enhance and amplify the inflammatory responses through many pathways, including enhancing the phagocytosis of macrophages, forming MAC to cause cell death, inducing many inflammatory mediators and recruiting inflammatory cells. ${ }^{160}$ On the other hand, lipoproteins also compete with CFH for binding sites in Bruch's membrane. ${ }^{161}$

CEP can activate specific T cells to cause inflammatory M1 polarization of retinal macrophages to induce dry AMD, and are also involved in the TLR2-induced neovascularization, considered as an early marker of high-risk AMD development. ${ }^{162-164}$ M2-like macrophages produced MMPs, which enhanced the penetration of CNV through Bruch's membrane, while M1 macrophages ameliorated CNV. ${ }^{165-169}$ Previous studies also showed that CNV could be inhibited by downregulating M1 macrophage/microglia polarization. ${ }^{170}$ Allingham et al suggested that the early recruitment of inflammatory M1 macrophages promoted the induction and initial development of CNV, followed by the sustained recruitment of reparative M2 macrophages that mediated the sustained CNV formation and growth. ${ }^{160}$ ALEs are found in drusen and Bruch's membrane of AMD patients, and act as haptens to induce autoantibody formation against lipid peroxide-modified retinal proteins, causing inflammatory responses and complement activation, and damaging the RPE cells. $^{171}$

A positive feedback loop of oxidative stress and related inflammation may be involved in the pathogenesis of AMD. ${ }^{172,173}$ In animal models, dietary supplementation with antioxidants and $\omega-3$ LCPUFA have been seen to rapidly modify the fatty acid content and to increase the retinal content of EPA by over $70 \%$ and protect the retina against lightinduced oxidative stress. ${ }^{174}$ Previous studies found that inhibition of inflammatory mediators, such as angiotensin II type 1 receptor blockers, ${ }^{175}$ reduced ROS as antioxidants such as N-acetyl-L-cysteine, ${ }^{154}$ saffron, ${ }^{108}$ vitamin C, E and zinc. ${ }^{110}$ In conclusion, oxidized lipoproteins increase oxidative stress, inflammation, and paracellular permeability of RPE cells, inducing outer blood retinal barrier dysfunction and causing VEGF production and wet AMD. ${ }^{176,177}$ 
An important target for lipid metabolism regulation is the peroxisome proliferator activated receptor (PPAR). ${ }^{178}$ Three different subtypes of PPAR have been isolated so far: $\alpha, \beta$, and $\gamma \cdot{ }^{179}$ Both DHA and EPA are the ligands of all the three PPAR isoforms. ${ }^{180}$ PPARs advance the entry of LCPUFA into mitochondria and peroxisomes, and regulate their metabolism ${ }^{181}$ via upregulating the expression of carnitine palmitoyl translocase, fatty acyl CoA dehydrogenase, and fatty acyl CoA dehydrogenase. ${ }^{113,182}$ PPARs were reported to enhance the phagocytosis of apoptotic cells by macrophages, ${ }^{183}$ promote M2 macrophage polarization, ${ }^{184}$ reduce MMP2 and MMP9, and inhibit CNV. ${ }^{114}$ They are also necessary for $\omega-3$ LCPUFA to attenuate retinal neovascularization in mice. ${ }^{181}$ Fontaine et al found that A2E promoted inflammation and angiogenesis partially via inducing the transactivation of PPARs and retinoid X receptors (RXR) in RPE cells. ${ }^{185,186}$ PPAR $\gamma$ coactivator (PGC)-1 $\alpha$ is a protein that increases RPE metabolism, maintains mitochondrial homeostasis, and protects against ROS damage. ${ }^{187}$ Zhang et al found that PGC- $1 \alpha^{-/-}$mice on a high-fat diet were more prone to developing AMD. ${ }^{188}$ Loss of nuclear factor-erythroid 2-related factor-2 and PGC-1 $\alpha$ leads to RPE damage and dry AMD. ${ }^{189}$ Strong light stimulation not only enhances POS phagocytosis in RPE cells but also induces activation of the PGC- $1 \alpha /$ EER $\alpha$ pathway, upregulating VEGF. ${ }^{181}$ Therefore, targeting PGC- $1 \alpha$ may be considered in anti-VEGF strategies to increase its efficacy for wet AMD. ${ }^{190}$ PPARs and PGC-1 $\alpha$ can regulate retinal lipid metabolism, and are avenues to manipulate in the treatment of diseases.

\section{LCPUFA Metabolism Regulates Autophagy and Senescence}

Autophagy is a protective, homeostatic mechanism, which is designed to remove faulty cellular components. ${ }^{191}$ Compromised autophagy can result in dysfunctional RPE and induce an AMD-like phenotype in mice. ${ }^{192}$ Toxic LCPUFA peroxidation products are mainly metabolized and cleared by lysosomal enzymes. ${ }^{154}$ RPE lysosomal enzymes are important regulators in this process and targets of lipid peroxide-mediated damages. ${ }^{193}$ Previous studies indicated that phagocytosis of lipid peroxide increased lipofuscin production and disrupted cell self-renewal through autophagy, resulting in release of undegraded POS proteins to the drusen. ${ }^{194,195}$ Drusen contain lipids, carbohydrates, proteins, and cellular debris that are processed by autophagy. ${ }^{196}$ It is well known that disturbed autophagy is one of the characteristics of AMD. ${ }^{197}$

In early AMD, RPE cells increase autophagy in response to acute oxidative stress. However, at the late stage of $\mathrm{AMD}$, the autophagic process is unable to cope with the increased number of damaged organelles. ${ }^{198}$ Autophagy inhibition leads to inflammasome activation and increased angiogenesis in RPE, and NLRP3 inflammasome activation induces pyroptosis. ${ }^{199}$ In addition, lipid peroxide-related lysosomal dysfunction induces VEGF secretion from RPE cells, causing CNV generation and leading to wet AMD. ${ }^{200}$

A2E induces autophagy by activating the Akt/mTOR pathway in RPE cells. ${ }^{199}$ The combination of A2E and autophagy inhibitor 3-methyladenine upregulates inflammation-related proteins IL-1 $\beta$, IL-2, IL-6 and IL-8, promoting the production of ROS and leading to RPE cell death. ${ }^{201}$ Rapamycin augments A2E-mediated autophagy and downregulates inflammatory factors and VEGF. ${ }^{202}$ Impaired autophagy or mitophagy in RPE cells leads to macrophage recruitment and inflammasome activation, thereby promoting RPE and photoreceptor degeneration. ${ }^{203}$ Several researches implicated impaired mitochondria in AMD. ${ }^{204,205}$ When the mitochondrial membrane is damaged, mitochondrial DNA, apoptosis-inducing factors and cytochrome $\mathrm{c}$ can be released, causing mitophagy, leading to necroptosis or pyroptosis and triggering chronic sterile inflammation. ${ }^{206}$

Elovanoids (ELVs) are a class of endogenous pro-homeostatic mediators synthesized from DHA. ${ }^{207}$ When retinal cells need to counteract neuroinflammatory responses to protect their integrity and to sustain survival and functions, ELVs are made rapidly. ${ }^{208}$ In AMD, amyloid- $\beta$ peptide accumulates in the subretinal drusen. ELV was reported to abolish the destructive effects of RPE, preventing inflammation, autophagy, extracellular matrix remodeling and AMD. ${ }^{209}$

Senescence is a state of permanent inhibition of cell growth and an important pathological mechanism of AMD. ${ }^{177} \mathrm{~A}$ large number of immune cells are present in the choroidal circulation. ${ }^{210}$ Senescent immune cells reduce phagocytosis and clearance, and induce angiogenesis and pro-inflammatory mediators such as IL-6, IL-8 and TNF- $\alpha,{ }^{211}$ which are collectively known as aging-related secretory phenotype. ${ }^{192}$ These cytokines promote a series of inflammatory cascades, and induce age-related inflammatory reactions, metabolic disorders, and chronic diseases. ${ }^{212}$ Chronic sterile inflammation may be the core of AMD. ${ }^{213}$ 
Senescence decreases the biosynthetic capacity of LCPUFA. ${ }^{214}$ Omega-3 LCPUFA supplementation can improve brain neurocognitive functions, limit neuroinflammation and stress response defects in aged animal models and clinical trials. ${ }^{215-218}$ Meanwhile, peroxide products of LCPUFA, such as A2E, can cause telomere dysfunction and accelerate RPE cell senescence. ${ }^{219}$

\section{Conclusion}

Dyslipidemia and chronic inflammation are both the manifestations of aging, and the common pathogenic factors of many age-related diseases. Oxidative stress, lipid disorder and inflammation are closely related. First, the metabolites of LCPUFA include anti-inflammatory and pro-inflammatory regulatory factors. Second, the peroxidation products of lipids promote the inflammatory process via activating complement and inflammasomes, and recruiting immune cells. Third, LCPUFA metabolism regulates inflammatory responses via modulating senescence and autophagy. The deposited lipids cause chronic sterile inflammation and innate immune responses. The combination of direct damage of oxidized lipid and maladjusted chronic inflammation leads to RPE degeneration, photoreceptor cell death, visual loss and macular degeneration. ${ }^{43}$ Many drug targets have been identified to alleviate AMD. Epidemiological, clinical, and experimental studies have shown that $\omega-3$ LCPUFA are associated with a decreased risk of AMD and that $\omega-6$ LCPUFA are associated with an increased risk. ${ }^{63,220}$

\section{Acknowledgments}

This study was supported by National Natural Science Foundation of China (81800429), Nature Science Foundation of Hubei Province (2020CFB612), Young and Middle-Aged Medical Backbone Talents of Wuhan (WHQG201902), Application Foundation Frontier Project of Wuhan (2020020601012221), Zhongnan Hospital of Wuhan University Science, Technology and Innovation Seed Fund (znpy2019001), and Translational Medicine and Interdisciplinary Research Joint Fund of Zhongnan Hospital of Wuhan University (ZNJC202007).

\section{Disclosure}

The authors report no conflicts of interest in this work.

\section{References}

1. Vogl WD, Bogunovic H, Waldstein SM, Riedl S, Schmidt-Erfurth U. Spatio-temporal alterations in retinal and choroidal layers in the progression of age-related macular degeneration (AMD) in optical coherence tomography. Sci Rep. 2021;11(1):5743. doi:10.1038/s41598021-85110-y

2. Colijn JM, Buitendijk GHS, Prokofyeva E, et al. Prevalence of age-related macular degeneration in Europe: the past and the future. Ophthalmology. 2017;124(12):1753-1763. doi:10.1016/j.ophtha.2017.05.035

3. Wong WL, Su X, Li X, et al. Global prevalence of age-related macular degeneration and disease burden projection for 2020 and 2040 : a systematic review and meta-analysis. Lancet Glob Health. 2014;2(2):e106-16. doi:10.1016/S2214-109X(13)70145-1

4. Domalpally A, Clemons TE, Danis RP, et al.; Writing Committee for the OPRs. Peripheral retinal changes associated with age-related macular degeneration in the age-related eye disease study 2: age-related eye disease study 2 report number 12 by the age-related eye disease study 2 Optos PEripheral RetinA (OPERA) Study Research Group. Ophthalmology. 2017;124(4):479-487. doi:10.1016/j.ophtha.2016.12.004

5. Jhingan M, Singh SR, Samanta A, et al. Drusen ooze: predictor for progression of dry age-related macular degeneration. Graefes Arch Clin Exp Ophthalmol. 2021;259(9):2687-2694. doi:10.1007/s00417-021-05147-7

6. Tsujinaka H, Fu J, Shen J, et al. Sustained treatment of retinal vascular diseases with self-aggregating sunitinib microparticles. Nat Commun. 2020;11(1):694. doi:10.1038/s41467-020-14340-x

7. Remmerie A, Scott CL. Macrophages and lipid metabolism. Cell Immunol. 2018;330:27-42. doi:10.1016/j.cellimm.2018.01.020

8. Mukhtar S, Ambati BK. The value of nutritional supplements in treating age-related macular degeneration: a review of the literature. Int Ophthalmol. 2019;39(12):2975-2983. doi:10.1007/s10792-019-01140-6

9. Pennington KL, DeAngelis MM. Epidemiology of age-related macular degeneration (AMD): associations with cardiovascular disease phenotypes and lipid factors. Eye Vis (Lond). 2016;3:34. doi:10.1186/s40662-016-0063-5

10. Chapman NA, Jacobs RJ, Braakhuis AJ. Role of diet and food intake in age-related macular degeneration: a systematic review. Clin Exp Ophthalmol. 2019;47(1):106-127. doi:10.1111/ceo.13343

11. DeAngelis MM, Owen LA, Morrison MA, et al. Genetics of age-related macular degeneration (AMD). Hum Mol Genet. 2017;26(R2):R246.

12. Chen L, Ma B, Liu X, Hao Y, Yang X, Liu M. H2 O2 induces oxidative stress damage through the BMP-6/SMAD/hepcidin axis. Dev Growth Differ. 2020;62(2):139-146. doi:10.1111/dgd.12650

13. Bonilha VL. Oxidative stress regulation and DJ-1 function in the retinal pigment epithelium: implications for AMD. Adv Exp Med Biol. 2018;1074:3-9. 
14. Moreira-Neto CA, Moult EM, Fujimoto JG, Waheed NK, Ferrara D. Choriocapillaris loss in advanced age-related macular degeneration. $J$ Ophthalmol. 2018;2018:8125267. doi:10.1155/2018/8125267

15. Nassisi M, Baghdasaryan E, Borrelli E, Ip M, Sadda SR. Choriocapillaris flow impairment surrounding geographic atrophy correlates with disease progression. PLoS One. 2019;14(2):e0212563. doi:10.1371/journal.pone.0212563

16. Fang Y, Du R, Jonas JB, et al. Ridge-shaped macula progressing parallel to bruch membrane defects and macular suprachoroidal cavitation. Retina. 2020;40(3):456-460. doi:10.1097/IAE.000000000002404

17. Munoz-Ramon PV, Hernandez Martinez P, Munoz-Negrete FJ. New therapeutic targets in the treatment of age-related macular degeneration. Arch Soc Esp Oftalmol. 2020;95(2):75-83. doi:10.1016/j.oftal.2019.09.011

18. Rozing MP, Durhuus JA, Krogh Nielsen M, et al. Age-related macular degeneration: a two-level model hypothesis. Prog Retin Eye Res. 2020;76:100825. doi:10.1016/j.preteyeres.2019.100825

19. Di Cara F, Andreoletti P, Trompier D, et al. Peroxisomes in immune response and inflammation. Int J Mol Sci. 2019;20(16):3877. doi:10.3390/ ijms20163877

20. Karahan M, Hazar L, Erdem S, et al. Is there a relationship between hematological inflammatory parameters and age-related macular degeneration? Ther Adv Ophthalmol. 2021;13:25158414211010550. doi:10.1177/25158414211010550

21. Pujol-Lereis LM, Schafer N, Kuhn LB, Rohrer B, Pauly D. Interrelation between oxidative stress and complement activation in models of agerelated macular degeneration. Adv Exp Med Biol. 2016;854:87-89.

22. Brandstetter C, Mohr LK, Latz E, Holz FG, Krohne TU. Light induces NLRP3 inflammasome activation in retinal pigment epithelial cells via lipofuscin-mediated photooxidative damage. $J$ Mol Med (Berl). 2015;93(8):905-916. doi:10.1007/s00109-015-1275-1

23. Iriyama A, Inoue Y, Takahashi H, Tamaki Y, Jang WD, Yanagi Y. A2E, a component of lipofuscin, is pro-angiogenic in vivo. J Cell Physiol. 2009;220(2):469-475. doi:10.1002/jcp.21792

24. Chandra S, Arpa C, Menon D, et al. Ten-year outcomes of antivascular endothelial growth factor therapy in neovascular age-related macular degeneration. Eye (Lond). 2020;34(10):1888-1896. doi:10.1038/s41433-020-0764-9

25. Jiang P, Chaparro FJ, Cuddington CT, et al. Injectable biodegradable bi-layered capsule for sustained delivery of bevacizumab in treating wet age-related macular degeneration. J Control Release. 2020;320:442-456. doi:10.1016/j.jconrel.2020.01.036

26. Subhi Y, Sorensen TL. Neovascular age-related macular degeneration in the very old ( $>/=90$ years): epidemiology, adherence to treatment, and comparison of efficacy. J Ophthalmol. 2017;2017:7194927. doi:10.1155/2017/7194927

27. Barth T, Reiners M, Zeman F, Greslechner R, Helbig H, Gamulescu MA. [Anti-VEGF-therapy of fibrovascular and serous-vascularized pigment epithelial detachment in neovascular AMD: a retrospective five-year-analysis]. Ophthalmologe. 2021;118(12):1255-1263. German.

28. Mettu PS, Allingham MJ, Cousins SW. Incomplete response to anti-VEGF therapy in neovascular AMD: exploring disease mechanisms and therapeutic opportunities. Prog Retin Eye Res. 2021;82:100906. doi:10.1016/j.preteyeres.2020.100906

29. Granstam E, Aurell S, Sjovall K, Paul A. Switching anti-VEGF agent for wet AMD: evaluation of impact on visual acuity, treatment frequency and retinal morphology in a real-world clinical setting. Graefes Arch Clin Exp Ophthalmol. 2021;259(8):2085-2093. doi:10.1007/s00417-02005059-y

30. Garweg JG, Gerhardt C. Disease stability and extended dosing under anti-VEGF treatment of exudative age-related macular degeneration (AMD) - a meta-analysis. Graefes Arch Clin Exp Ophthalmol. 2021;259(8):2181-2192. doi:10.1007/s00417-020-05048-1

31. Thalgott V, Feucht N, Lohmann CP, Maier M. [Long-term results in neovascular age-related macular degeneration: changes in visual acuity and geographic atrophy during long-standing anti-VEGF therapy]. Ophthalmologe. 2016;113(8):668-674. German. doi:10.1007/s00347-016-0228-6

32. Toth CA, Tai V, Pistilli M, et al. Distribution of OCT features within areas of macular atrophy or Scar after 2 years of anti-VEGF treatment for neovascular AMD in CATT. Ophthalmol Retina. 2019;3(4):316-325. German. doi:10.1016/j.oret.2018.11.011

33. Bilgic A, Kodjikian L, Chhablani J, et al. Sustained intraocular pressure rise after the treat and extend regimen at 3 years: aflibercept versus ranibizumab. J Ophthalmol. 2020;2020:7462098. doi:10.1155/2020/7462098

34. Lee JM, Bae HW, Lee SY, Seong GJ, Kim CY. Effect of anti-vascular endothelial growth factor antibody on the survival of cultured retinal ganglion cells. Korean J Ophthalmol. 2017;31(4):360-365. doi:10.3341/kjo.2017.0054

35. Kim SY, Yoon MH, Chin HS. Changes in the ganglion cell-inner plexiform layer after consecutive intravitreal injections of anti-vascular endothelial growth factor in age-related macular degeneration patients. Korean J Ophthalmol. 2020;34(1):11-18. doi:10.3341/kjo.2019.0081

36. Liu A, Chang J, Lin Y, Shen Z, Bernstein PS. Long-chain and very long-chain polyunsaturated fatty acids in ocular aging and age-related macular degeneration. J Lipid Res. 2010;51(11):3217-3229. doi:10.1194/jlr.M007518

37. McGrattan AM, McGuinness B, McKinley MC, et al. Diet and inflammation in cognitive ageing and Alzheimer's disease. Curr Nutr Rep. 2019;8(2):53-65. doi:10.1007/s13668-019-0271-4

38. Miller JW. Beyond VEGF-The Weisenfeld Lecture. Invest Ophthalmol Vis Sci. 2016;57(15):6911-6918. doi:10.1167/iovs.16-21201

39. Xu Q, Cao S, Rajapakse S, Matsubara JA. Understanding AMD by analogy: systematic review of lipid-related common pathogenic mechanisms in AMD, AD, AS and GN. Lipids Health Dis. 2018;17(1):3. doi:10.1186/s12944-017-0647-7

40. Gorusupudi A, Liu A, Hageman GS, Bernstein PS. Associations of human retinal very long-chain polyunsaturated fatty acids with dietary lipid biomarkers. J Lipid Res. 2016;57(3):499-508. doi:10.1194/jlr.P065540

41. Jacob J, Mangelschots E, Michez M, Sanak SN, Leys A. Cross-Sectional Study on vitamin D, zinc oxide and fatty acid status in a population with a moderate to high risk of AMD identified by the STARS((R)) questionnaire. Ophthalmol Ther. 2021;10(2):299-311. doi:10.1007/s40123021-00335-4

42. Fernandez-Vega B, Garcia M, Olivares L, et al. The association study of lipid metabolism gene polymorphisms with AMD identifies a protective role for APOE-E2 allele in the wet form in a Northern Spanish population. Acta Ophthalmol. 2020;98(3):e282-e91. doi:10.1111/ aos. 14280

43. Jun S, Datta S, Wang L, Pegany R, Cano M, Handa JT. The impact of lipids, lipid oxidation, and inflammation on AMD, and the potential role of miRNAs on lipid metabolism in the RPE. Exp Eye Res. 2019;181:346-355. doi:10.1016/j.exer.2018.09.023

44. Bazan NG. Cell survival matters: docosahexaenoic acid signaling, neuroprotection and photoreceptors. Trends Neurosci. 2006;29(5):263-271. doi:10.1016/j.tins.2006.03.005

45. Schnebelen C, Viau S, Gregoire S, et al. Nutrition for the eye: different susceptibility of the retina and the lacrimal gland to dietary omega-6 and omega-3 polyunsaturated fatty acid incorporation. Ophthalmic Res. 2009;41(4):216-224. doi:10.1159/000217726 
46. Acar N, Berdeaux O, Gregoire S, et al. Lipid composition of the human eye: are red blood cells a good mirror of retinal and optic nerve fatty acids? PLoS One. 2012;7(4):e35102. doi:10.1371/journal.pone.0035102

47. Skowronska-Krawczyk D, Chao DL. Long-chain polyunsaturated fatty acids and age-related macular degeneration. Adv Exp Med Biol. 2019;1185:39-43.

48. Winkler TW, Grassmann F, Brandl C, et al. Genome-wide association meta-analysis for early age-related macular degeneration highlights novel loci and insights for advanced disease. BMC Med Genomics. 2020;13(1):120. doi:10.1186/s12920-020-00760-7

49. Leung $\mathrm{HH}, \mathrm{Ng} \mathrm{AL}$, Durand $\mathrm{T}$, et al. Increase in omega-6 and decrease in omega-3 polyunsaturated fatty acid oxidation elevates the risk of exudative AMD development in adults with Chinese diet. Free Radic Biol Med. 2019;145:349-356. doi:10.1016/j.freeradbiomed.2019.10.007

50. Merle BMJ, Buaud B, Korobelnik JF, et al. Plasma long-chain omega-3 polyunsaturated fatty acids and macular pigment in subjects with family history of age-related macular degeneration: the Limpia Study. Acta Ophthalmol. 2017;95(8):e763-e69. doi:10.1111/aos.13408

51. Meagher KA, Nolan JM, Beatty S. Regarding macular xanthophylls and omega-3 long-chain polyunsaturated fatty acids in age-related macular degeneration. JAMA Ophthalmol. 2014;132(2):230-231. doi:10.1001/jamaophthalmol.2013.6667

52. Suarez-Barrio C, Del Olmo-Aguado S, Garcia-Perez E, et al. Antioxidant role of PRGF on RPE cells after blue light insult as a therapy for neurodegenerative diseases. Int J Mol Sci. 2020;21(3):1021. doi:10.3390/ijms21031021

53. Shen HH, Peterson SJ, Bellner L, et al. Cold-pressed Nigella sativa oil standardized to $3 \%$ thymoquinone potentiates omega-3 protection against obesity-induced oxidative stress, inflammation, and markers of insulin resistance accompanied with conversion of white to Beige fat in mice. Antioxidants (Basel). 2020;9(6):489.

54. Harauma A, Yasuda H, Hatanaka E, Nakamura MT, Salem N Jr, Moriguchi T. The essentiality of arachidonic acid in addition to docosahexaenoic acid for brain growth and function. Prostaglandins Leukot Essent Fatty Acids. 2017;116:9-18. doi:10.1016/j.plefa.2016.11.002

55. Lister T. Nutritional, alternative, and complementary therapies for age-related macular degeneration. Integr Med (Encinitas). 2019;18(6):30-36.

56. Carneiro A, Andrade JP. Nutritional and lifestyle interventions for age-related macular degeneration: a review. Oxid Med Cell Longev. 2017;2017:6469138. doi:10.1155/2017/6469138

57. Wu J, Cho E, Giovannucci EL, et al. Dietary intakes of eicosapentaenoic acid and docosahexaenoic acid and risk of age-related macular degeneration. Ophthalmology. 2017;124(5):634-643. doi:10.1016/j.ophtha.2016.12.033

58. Christen WG, Schaumberg DA, Glynn RJ, Buring JE. Dietary omega-3 fatty acid and fish intake and incident age-related macular degeneration in women. Arch Ophthalmol. 2011;129(7):921-929. doi:10.1001/archophthalmol.2011.34

59. Yanai R, Chen S, Uchi SH, Nanri T, Connor KM, Kimura K. Attenuation of choroidal neovascularization by dietary intake of omega-3 longchain polyunsaturated fatty acids and lutein in mice. PLoS One. 2018;13(4):e0196037. doi:10.1371/journal.pone.0196037

60. Arslan S, Kadayifcilar S, Samur G. The potential role of dietary antioxidant capacity in preventing age-related macular degeneration. $J$ Am Coll Nutr. 2019;38(5):424-432. doi:10.1080/07315724.2018.1538830

61. SanGiovanni JP, Agron E, Clemons TE, Chew EY. Omega-3 long-chain polyunsaturated fatty acid intake inversely associated with 12-year progression to advanced age-related macular degeneration. Arch Ophthalmol. 2009;127(1):110-112. doi:10.1001/archophthalmol.2008.518

62. Aoki A, Inoue M, Nguyen E, et al. Dietary n-3 fatty acid, alpha-tocopherol, zinc, vitamin D, vitamin C, and beta-carotene are associated with age-related macular degeneration in Japan. Sci Rep. 2016;6:20723. doi:10.1038/srep20723

63. Roh M, Shin HJ, Lains I, et al. Higher intake of polyunsaturated fatty acid and monounsaturated fatty acid is inversely associated with AMD Invest Ophthalmol Vis Sci. 2020;61(2):20. doi:10.1167/iovs.61.2.20

64. Ho L, van leeuwen R, Witteman JC, et al. Reducing the genetic risk of age-related macular degeneration with dietary antioxidants, zinc, and omega-3 fatty acids: the Rotterdam study. Arch Ophthalmol. 2011;129(6):758-766. doi:10.1001/archophthalmol.2011.141

65. $\mathrm{Ng} \mathrm{AL}$, Leung $\mathrm{HH}$, Kawasaki R, et al. Dietary habits, fatty acids and carotenoid levels are associated with neovascular age-related macular degeneration in Chinese. Nutrients. 2019;11(8):1720. doi:10.3390/nu11081720

66. Van Asten F, Chiu CY, Agron E, et al. No CFH or ARMS2 interaction with omega-3 fatty acids, low versus high zinc, or beta-carotene versus lutein and zeaxanthin on progression of age-related macular degeneration in the age-related eye disease study 2: age-related eye disease study 2 report no. 18. Ophthalmology. 2019;126(11):1541-1548. doi:10.1016/j.ophtha.2019.06.004

67. Souied EH, Delcourt C, Querques G, et al. Oral docosahexaenoic acid in the prevention of exudative age-related macular degeneration: the Nutritional AMD Treatment 2 study. Ophthalmology. 2013;120(8):1619-1631. doi:10.1016/j.ophtha.2013.01.005

68. Korobelnik JF, Rougier MB, Delyfer MN, et al. Effect of dietary supplementation with lutein, zeaxanthin, and omega-3 on macular pigment: a randomized clinical trial. JAMA Ophthalmol. 2017;135(11):1259-1266. doi:10.1001/jamaophthalmol.2017.3398

69. Acar N, Merle BMJ, Ajana S, et al. Predicting the retinal content in omega-3 fatty acids for age-related macular-degeneration. Clin Transl Med 2021;11(7):e404. doi:10.1002/ctm2.404

70. Agron E, Mares J, Clemons TE, et al. Dietary nutrient intake and progression to late age-related macular degeneration in the age-related eye disease studies 1 and 2. Ophthalmology. 2021;128(3):425-442. doi:10.1016/j.ophtha.2020.08.018

71. Hellstrom A, Pivodic A, Granse L, et al. Association of docosahexaenoic acid and arachidonic acid serum levels with retinopathy of prematurity in preterm infants. JAMA Netw Open. 2021;4(10):e2128771. doi:10.1001/jamanetworkopen.2021.28771

72. Hellstrom A, Nilsson AK, Wackernagel D, et al. Effect of enteral lipid supplement on severe retinopathy of prematurity: a randomized clinical trial. JAMA Pediatr. 2021;175(4):359-367. doi:10.1001/jamapediatrics.2020.5653

73. Romero-Vazquez S, Llorens V, Soler-Boronat A, Figueras-Roca M, Adan A, Molins B. Interlink between inflammation and oxidative stress in age-related macular degeneration: role of complement Factor H. Biomedicines. 2021;9(7):763. doi:10.3390/biomedicines9070763

74. Caceres PS, Rodriguez-Boulan E. Retinal pigment epithelium polarity in health and blinding diseases. Curr Opin Cell Biol. 2020;62:37-45. doi:10.1016/j.ceb.2019.08.001

75. Song Y, Tian X, Wang X, Feng H. Vascular protection of salicin on IL-1beta-induced endothelial inflammatory response and damages in retinal endothelial cells. Artif Cells Nanomed Biotechnol. 2019;47(1):1995-2002. doi:10.1080/21691401.2019.1608220

76. Cheng SC, Huang WC, S Pang JH, Wu YH, Cheng CY. Quercetin inhibits the production of IL-1beta-induced inflammatory cytokines and chemokines in ARPE-19 cells via the MAPK and NF-kappaB signaling pathways. Int J Mol Sci. 2019;20(12):2957. doi:10.3390/ijms20122957

77. Ten Berge JC, Fazil Z, van den Born I, et al. Intraocular cytokine profile and autoimmune reactions in retinitis pigmentosa, age-related macular degeneration, glaucoma and cataract. Acta Ophthalmol. 2019;97(2):185-192. doi:10.1111/aos.13899 
78. Knickelbein JE, Chan CC, Sen HN, Ferris FL, Nussenblatt RB. Inflammatory mechanisms of age-related macular degeneration. Int Ophthalmol Clin. 2015;55(3):63-78. doi:10.1097/IIO.0000000000000073

79. Wang H, Han X, Wittchen ES, Hartnett ME. TNF-alpha mediates choroidal neovascularization by upregulating VEGF expression in RPE through ROS-dependent beta-catenin activation. Mol Vis. 2016;22:116-128.

80. Lavalette S, Raoul W, Houssier M, et al. Interleukin-1beta inhibition prevents choroidal neovascularization and does not exacerbate photoreceptor degeneration. Am J Pathol. 2011;178(5):2416-2423. doi:10.1016/j.ajpath.2011.01.013

81. Chen X, Han R, Hao P, et al. Nepetin inhibits IL-1beta induced inflammation via NF-kappaB and MAPKs signaling pathways in ARPE-19 cells. Biomed Pharmacother. 2018;101:87-93. doi:10.1016/j.biopha.2018.02.054

82. Tan W, Zou J, Yoshida S, Jiang B, Zhou Y. The role of inflammation in age-related macular degeneration. Int J Biol Sci. 2020;16(15):29893001. doi:10.7150/ijbs. 49890

83. Ogura S, Baldeosingh R, Bhutto IA, et al. A role for mast cells in geographic atrophy. FASEB J. 2020;34(8):10117-10131. doi:10.1096/ fj.202000807R

84. McLeod DS, Bhutto I, Edwards MM, Gedam M, Baldeosingh R, Lutty GA. Mast cell-derived tryptase in geographic atrophy. Invest Ophthalmol Vis Sci. 2017;58(13):5887-5896. doi:10.1167/iovs.17-22989

85. Clare AJ, Liu J, Copland DA, Theodoropoulou S, Dick AD. Unravelling the therapeutic potential of IL-33 for atrophic AMD. Eye (Lond). 2021. doi:10.1038/s41433-021-01725-5

86. Chen J, Wang W, Li Q. Increased Th1/Th17 responses contribute to low-grade inflammation in age-related macular degeneration. Cell Physiol Biochem. 2017;44(1):357-367. doi:10.1159/000484907

87. Ishikawa K, Kannan R, Hinton DR. Molecular mechanisms of subretinal fibrosis in age-related macular degeneration. Exp Eye Res. 2016;142:19-25. doi:10.1016/j.exer.2015.03.009

88. Nozaki M, Raisler BJ, Sakurai E, et al. Drusen complement components C3a and C5a promote choroidal neovascularization. Proc Natl Acad Sci U S A. 2006;103(7):2328-2333. doi:10.1073/pnas.0408835103

89. Bora PS, Sohn JH, Cruz JM, et al. Role of complement and complement membrane attack complex in laser-induced choroidal neovascularization. J Immunol. 2005;174(1):491-497. doi:10.4049/jimmunol.174.1.491

90. Sakamoto S, Takahashi H, Tan X, et al. Changes in multiple cytokine concentrations in the aqueous humour of neovascular age-related macular degeneration after 2 months of ranibizumab therapy. Br J Ophthalmol. 2018;102(4):448-454. doi:10.1136/bjophthalmol-2017-310284

91. Yuan J. Role of inflammatory factors in the effects of aflibercept or ranibizumab treatment for alleviating wet age-associated macular degeneration. Exp Ther Med. 2019;17(5):4249-4258. doi:10.3892/etm.2019.7427

92. Sato T, Takeuchi M, Karasawa Y, Enoki T, Ito M. Intraocular inflammatory cytokines in patients with neovascular age-related macular degeneration before and after initiation of intravitreal injection of anti-VEGF inhibitor. Sci Rep. 2018;8(1):1098. doi:10.1038/s41598-01819594-6

93. Clark SJ, Bishop PN. The eye as a complement dysregulation hotspot. Semin Immunopathol. 2018;40(1):65-74. doi:10.1007/s00281-017-0649-6

94. Zhang X, Sivaprasad S. Drusen and pachydrusen: the definition, pathogenesis, and clinical significance. Eye (Lond). 2021;35(1):121-133. doi:10.1038/s41433-020-01265-4

95. Tarallo V, Hirano Y, Gelfand BD, et al. DICER1 loss and Alu RNA induce age-related macular degeneration via the NLRP3 inflammasome and MyD88. Cell. 2012;149(4):847-859. doi:10.1016/j.cell.2012.03.036

96. Kassa E, Ciulla TA, Hussain RM, Dugel PU. Complement inhibition as a therapeutic strategy in retinal disorders. Expert Opin Biol Ther. 2019;19(4):335-342. doi:10.1080/14712598.2019.1575358

97. Ebrahimi KB, Fijalkowski N, Cano M, Handa JT. Decreased membrane complement regulators in the retinal pigmented epithelium contributes to age-related macular degeneration. J Pathol. 2013;229(5):729-742. doi:10.1002/path.4128

98. Vogt SD, Curcio CA, Wang L, et al. Retinal pigment epithelial expression of complement regulator CD46 is altered early in the course of geographic atrophy. Exp Eye Res. 2011;93(4):413-423. doi:10.1016/j.exer.2011.06.002

99. Yerramothu P, Vijay AK, Willcox MDP. Inflammasomes, the eye and anti-inflammasome therapy. Eye (Lond). 2018;32(3):491-505. doi:10.1038/eye.2017.241

100. Kauppinen A, Paterno JJ, Blasiak J, Salminen A, Kaarniranta K. Inflammation and its role in age-related macular degeneration. Cell Mol Life Sci. 2016;73(9):1765-1786. doi:10.1007/s00018-016-2147-8

101. Tseng WA, Thein T, Kinnunen K, et al. NLRP3 inflammasome activation in retinal pigment epithelial cells by lysosomal destabilization: implications for age-related macular degeneration. Invest Ophthalmol Vis Sci. 2013;54(1):110-120. doi:10.1167/iovs.12-10655

102. Pool FM, Kiel C, Serrano L, Luthert PJ. Repository of proposed pathways and protein-protein interaction networks in age-related macular degeneration. NPJ Aging Mech Dis. 2020;6:2. doi:10.1038/s41514-019-0039-5

103. Lee KS, Lin S, Copland DA, Dick AD, Liu J. Cellular senescence in the aging retina and developments of senotherapies for age-related macular degeneration. J Neuroinflammation. 2021;18(1):32. doi:10.1186/s12974-021-02088-0

104. Chen W, Esselman WJ, Jump DB, Busik JV. Anti-inflammatory effect of docosahexaenoic acid on cytokine-induced adhesion molecule expression in human retinal vascular endothelial cells. Invest Ophthalmol Vis Sci. 2005;46(11):4342-4347. doi:10.1167/iovs.05-0601

105. Zhao Y, Joshi-Barve S, Barve S, Chen LH. Eicosapentaenoic acid prevents LPS-induced TNF-alpha expression by preventing NF-kappaB activation. J Am Coll Nutr. 2004;23(1):71-78. doi:10.1080/07315724.2004.10719345

106. Wang TM, Chen CJ, Lee TS, et al. Docosahexaenoic acid attenuates VCAM-1 expression and NF-kappaB activation in TNF-alpha-treated human aortic endothelial cells. J Nutr Biochem. 2011;22(2):187-194. doi:10.1016/j.jnutbio.2010.01.007

107. Devassy JG, Leng S, Gabbs M, Monirujjaman M, Aukema HM. Omega-3 polyunsaturated fatty acids and oxylipins in neuroinflammation and management of Alzheimer disease. Adv Nutr. 2016;7(5):905-916. doi:10.3945/an.116.012187

108. Nakamura M, Kuse Y, Tsuruma K, Shimazawa M, Hara H. The involvement of the oxidative stress in murine blue LED light-induced retinal damage model. Biol Pharm Bull. 2017;40(8):1219-1225. doi:10.1248/bpb.b16-01008

109. Heitmar R, Brown J, Kyrou I. Saffron (Crocus sativus L.) in ocular diseases: a narrative review of the existing evidence from clinical studies. Nutrients. 2019;11(3):649. doi:10.3390/nu11030649

110. Evans JR, Lawrenson JG. Antioxidant vitamin and mineral supplements for slowing the progression of age-related macular degeneration. Cochrane Database Syst Rev. 2017;7:CD000254. doi:10.1002/14651858.CD000254.pub4 
111. Delmas D, Cornebise C, Courtaut F, Xiao J, Aires V. New highlights of resveratrol: a review of properties against ocular diseases. Int J Mol Sci. 2021;22(3):1295. doi:10.3390/ijms22031295

112. Blasiak J, Pawlowska E, Chojnacki J, Szczepanska J, Chojnacki C, Kaarniranta K. Zinc and autophagy in age-related macular degeneration. Int J Mol Sci. 2020;21(14):4994. doi:10.3390/ijms21144994

113. Vallee A, Lecarpentier Y, Guillevin R, Vallee JN. PPARgamma agonists: potential treatments for exudative age-related macular degeneration. Life Sci. 2017;188:123-130. doi:10.1016/j.1fs.2017.09.008

114. Fu Z, Liegl R, Wang Z, et al. Adiponectin mediates dietary omega-3 long-chain polyunsaturated fatty acid protection against choroidal neovascularization in mice. Invest Ophthalmol Vis Sci. 2017;58(10):3862-3870. doi:10.1167/iovs.17-21796

115. Nashine S. Potential therapeutic candidates for age-related macular degeneration (AMD). Cells. 2021;10(9):2483. doi:10.3390/cells10092483

116. Zhang R, Liu Z, Zhang H, Zhang Y, Lin D. The COX-2-selective antagonist (NS-398) inhibits choroidal neovascularization and subretinal fibrosis. PLoS One. 2016;11(1):e0146808. doi:10.1371/journal.pone.0146808

117. Qiu F, Matlock G, Chen Q, et al. Therapeutic effects of PPARalpha agonist on ocular neovascularization in models recapitulating neovascular age-related macular degeneration. Invest Ophthalmol Vis Sci. 2017;58(12):5065-5075. doi:10.1167/iovs.17-22091

118. Sulaiman RS, Park B, Sheik Pran Babu SP, et al. Chemical proteomics reveals soluble epoxide hydrolase as a therapeutic target for ocular neovascularization. ACS Chem Biol. 2018;13(1):45-52. doi:10.1021/acschembio.7b00854

119. Sulaiman RS, Merrigan S, Quigley J, et al. A novel small molecule ameliorates ocular neovascularisation and synergises with anti-VEGF therapy. Sci Rep. 2016;6:25509. doi:10.1038/srep25509

120. Kojetin DJ, Burris TP. REV-ERB and ROR nuclear receptors as drug targets. Nat Rev Drug Discov. 2014;13(3):197-216. doi:10.1038/nrd4100

121. Zapadka TE, Lindstrom SI, Taylor BE, et al. RORgammat inhibitor-SR1001 Halts retinal inflammation, capillary degeneration, and the progression of diabetic retinopathy. Int J Mol Sci. 2020;21(10):3547. doi:10.3390/ijms21103547

122. Fu Z, Sun Y, Cakir B, et al. Targeting neurovascular interaction in retinal disorders. Int J Mol Sci. 2020;21(4):1503. doi:10.3390/ijms21041503

123. Jaffe GJ, Westby K, Csaky KG, et al. C5 inhibitor avacincaptad pegol for geographic atrophy due to age-related macular degeneration: a Randomized Pivotal Phase 2/3 Trial. Ophthalmology. 2021;128(4):576-586. doi:10.1016/j.ophtha.2020.08.027

124. Sapieha P, Stahl A, Chen J, et al. 5-Lipoxygenase metabolite 4-HDHA is a mediator of the antiangiogenic effect of omega-3 polyunsaturated fatty acids. Sci Transl Med. 2011;3(69):69ra12. doi:10.1126/scitranslmed.3001571

125. Nelson AJ, Stephenson DJ, Cardona CL, et al. Macrophage polarization is linked to Ca(2+)-independent phospholipase A2 beta-derived lipids and cross-cell signaling in mice. J Lipid Res. 2020;61(2):143-158. doi:10.1194/jlr.RA119000281

126. Joffre C, Rey C, Laye S. N-3 polyunsaturated fatty acids and the resolution of neuroinflammation. Front Pharmacol. 2019;10:1022. doi:10.3389/fphar.2019.01022

127. Elmasry K, Ibrahim AS, Abdulmoneim S, Al-Shabrawey M. Bioactive lipids and pathological retinal angiogenesis. Br J Pharmacol. $2019 ; 176$ (1):93-109. doi:10.1111/bph.14507

128. Leuti A, Maccarrone M, Chiurchiu V. Proresolving lipid mediators: endogenous modulators of oxidative stress. Oxid Med Cell Longev. 2019;2019:8107265. doi:10.1155/2019/8107265

129. Rivera JC, Dabouz R, Noueihed B, Omri S, Tahiri H, Chemtob S. Ischemic retinopathies: oxidative stress and inflammation. Oxid Med Cell Longev. 2017;2017:3940241. doi:10.1155/2017/3940241

130. Calder PC. n-3 PUFA and inflammation: from membrane to nucleus and from bench to bedside. Proc Nutr Soc. 2020;79:404-416.

131. Kuhn H, Banthiya S, van Leyen K. Mammalian lipoxygenases and their biological relevance. Biochim Biophys Acta. 2015;1851(4):308-330. doi:10.1016/j.bbalip.2014.10.002

132. Subramanian P, Mendez EF, Becerra SP, Novel A. Inhibitor of 5-lipoxygenase (5-LOX) prevents oxidative stress-induced cell death of Retinal Pigment Epithelium (RPE) cells. Invest Ophthalmol Vis Sci. 2016;57(11):4581-4588. doi:10.1167/iovs.15-19039

133. Gong Y, Fu Z, Liegl R, Chen J, Hellstrom A, Smith LE. omega-3 and omega-6 long-chain PUFAs and their enzymatic metabolites in neovascular eye diseases. Am J Clin Nutr. 2017;106(1):16-26. doi:10.3945/ajcn.117.153825

134. Gubitosi-Klug RA, Talahalli R, Du Y, Nadler JL, Kern TS. 5-Lipoxygenase, but not 12/15-lipoxygenase, contributes to degeneration of retinal capillaries in a mouse model of diabetic retinopathy. Diabetes. 2008;57(5):1387-1393. doi:10.2337/db07-1217

135. Othman A, Ahmad S, Megyerdi S, et al. 12/15-Lipoxygenase-derived lipid metabolites induce retinal endothelial cell barrier dysfunction: contribution of NADPH oxidase. PLoS One. 2013;8(2):e57254. doi:10.1371/journal.pone.0057254

136. Arnold C, Konkel A, Fischer R, Schunck WH. Cytochrome P450-dependent metabolism of omega-6 and omega-3 long-chain polyunsaturated fatty acids. Pharmacol Rep. 2010;62(3):536-547. doi:10.1016/S1734-1140(10)70311-X

137. Fleming I. New lipid mediators in retinal angiogenesis and retinopathy. Front Pharmacol. 2019;10:739. doi:10.3389/fphar.2019.00739

138. Shao Z, Fu Z, Stahl A, et al. Cytochrome P450 $2 \mathrm{C} 8$ omega3-long-chain polyunsaturated fatty acid metabolites increase mouse retinal pathologic neovascularization-brief report. Arterioscler Thromb Vasc Biol. 2014;34(3):581-586. doi:10.1161/ATVBAHA.113.302927

139. Gong Y, Fu Z, Edin ML, et al. Cytochrome P450 oxidase $2 \mathrm{C}$ inhibition adds to omega-3 long-chain polyunsaturated fatty acids protection against retinal and choroidal neovascularization. Arterioscler Thromb Vasc Biol. 2016;36(9):1919-1927. doi:10.1161/ATVBAHA.116.307558

140. Hasegawa E, Inafuku S, Mulki L, et al. Cytochrome P450 monooxygenase lipid metabolites are significant second messengers in the resolution of choroidal neovascularization. Proc Natl Acad Sci U S A. 2017;114(36):E7545-E53. doi:10.1073/pnas.1620898114

141. Ontko CD, Capozzi ME, Kim MJ, McCollum GW, Penn JS. Cytochrome P450-epoxygenated fatty acids inhibit Muller glial inflammation. Sci Rep. 2021;11(1):9677. doi:10.1038/s41598-021-89000-1

142. Capozzi ME, Hammer SS, McCollum GW, Penn JS. Epoxygenated fatty acids inhibit retinal vascular inflammation. Sci Rep. $2016 ; 6: 39211$. doi:10.1038/srep39211

143. Gong Y, Shao Z, Fu Z, et al. Fenofibrate inhibits cytochrome P450 epoxygenase $2 \mathrm{C}$ activity to suppress pathological ocular angiogenesis. EBioMedicine. 2016;13:201-211. doi:10.1016/j.ebiom.2016.09.025

144. Parmar VM, Parmar T, Arai E, Perusek L, Maeda A. A2E-associated cell death and inflammation in retinal pigmented epithelial cells from human induced pluripotent stem cells. Stem Cell Res. 2018;27:95-104. doi:10.1016/j.scr.2018.01.014

145. Green CJ, Pramfalk C, Charlton CA, et al. Hepatic de novo lipogenesis is suppressed and fat oxidation is increased by omega-3 fatty acids at the expense of glucose metabolism. BMJ Open Diabetes Res Care. 2020;8(1):e000871. doi:10.1136/bmjdrc-2019-000871 
146. Xie H, Yin F, Liu Z, et al. Oxidation kinetics of polyunsaturated fatty acids esterified into triacylglycerols and phospholipids in dried scallop (Argopecten irradians) adductor muscles during storage. Food Funct. 2020;11(3):2349-2357. doi:10.1039/D0FO00051E

147. Cheng YS, Linetsky M, Gu X, Ayyash N, Gardella A, Salomon RG. Light-induced generation and toxicity of docosahexaenoate-derived oxidation products in retinal pigmented epithelial cells. Exp Eye Res. 2019;181:325-345. doi:10.1016/j.exer.2018.09.012

148. Kaarniranta K, Koskela A, Felszeghy S, Kivinen N, Salminen A, Kauppinen A. Fatty acids and oxidized lipoproteins contribute to autophagy and innate immunity responses upon the degeneration of retinal pigment epithelium and development of age-related macular degeneration. Biochimie. 2019;159:49-54. doi:10.1016/j.biochi.2018.07.010

149. Kim SY, Kambhampati SP, Bhutto IA, McLeod DS, Lutty GA, Kannan RM. Evolution of oxidative stress, inflammation and neovascularization in the choroid and retina in a subretinal lipid induced age-related macular degeneration model. Exp Eye Res. 2021;203:108391. doi:10.1016/j. exer.2020.108391

150. Datta S, Cano M, Ebrahimi K, Wang L, Handa JT. The impact of oxidative stress and inflammation on RPE degeneration in non-neovascular AMD. Prog Retin Eye Res. 2017;60:201-218. doi:10.1016/j.preteyeres.2017.03.002

151. Kaarniranta K, Tokarz P, Koskela A, Paterno J, Blasiak J. Autophagy regulates death of retinal pigment epithelium cells in age-related macular degeneration. Cell Biol Toxicol. 2017;33(2):113-128. doi:10.1007/s10565-016-9371-8

152. Li W, Cao T, Luo C, et al. Crosstalk between ER stress, NLRP3 inflammasome, and inflammation. Appl Microbiol Biotechnol. 2020;104 (14):6129-6140. doi:10.1007/s00253-020-10614-y

153. Celkova L, Doyle SL, Campbell M. NLRP3 inflammasome and pathobiology in AMD. J Clin Med. 2015;4(1):172-192. doi:10.3390/ jem4010172

154. Brandstetter C, Patt J, Holz FG, Krohne TU. Inflammasome priming increases retinal pigment epithelial cell susceptibility to lipofuscin phototoxicity by changing the cell death mechanism from apoptosis to pyroptosis. J Photochem Photobiol B. 2016;161:177-183. doi:10.1016/j. jphotobiol.2016.05.018

155. Gallo G, Sprovieri P, Martino G. 4-hydroxynonenal and oxidative stress in several organelles and its damaging effects on cell functions. $J$ Physiol Pharmacol. 2020;71(1):15-33.

156. Sharma A, Sharma R, Chaudhary P, et al. 4-Hydroxynonenal induces p53-mediated apoptosis in retinal pigment epithelial cells. Arch Biochem Biophys. 2008;480(2):85-94. doi:10.1016/j.abb.2008.09.016

157. Vatsyayan R, Chaudhary P, Sharma A, et al. Role of 4-hydroxynonenal in epidermal growth factor receptor-mediated signaling in retinal pigment epithelial cells. Exp Eye Res. 2011;92(2):147-154. doi:10.1016/j.exer.2010.11.010

158. Kaarniranta K, Kajdanek J, Morawiec J, Pawlowska E, Blasiak J. PGC-1alpha protects RPE cells of the aging retina against oxidative stressinduced degeneration through the regulation of senescence and mitochondrial quality control. The significance for AMD pathogenesis. Int $J$ Mol Sci. 2018;19(8):2317. doi:10.3390/ijms19082317

159. Lin CH, Wu MR, Huang WJ, Chow DS, Hsiao G, Cheng YW. Low-luminance blue light-enhanced phototoxicity in A2E-laden RPE cell cultures and rats. Int J Mol Sci. 2019;20(7):1799. doi:10.3390/ijms20071799

160. Allingham MJ, Loksztejn A, Cousins SW, Mettu PS. Immunological aspects of age-related macular degeneration. Adv Exp Med Biol. 2021;1256:143-189. doi:10.1007/978-3-030-66014-7_6

161. Meri S, Haapasalo K. Function and dysfunction of complement factor $\mathrm{H}$ during formation of lipid-rich deposits. Front Immunol. 2020;11:611830. doi:10.3389/fimmu.2020.611830

162. Ardeljan D, Tuo J, Chan CC. Carboxyethylpyrrole plasma biomarkers in age-related macular degeneration. Drugs Future. 2011;36(9):712-718. doi:10.1358/dof.2011.036.09.1678338

163. Koscielniak A, Serafin M, Duda M, et al. Oxidation-induced increase in photoreactivity of bovine retinal lipid extract. Cell Biochem Biophys. 2017;75(3-4):443-454. doi:10.1007/s12013-017-0832-3

164. Yang Y, Liu F, Tang M, et al. Macrophage polarization in experimental and clinical choroidal neovascularization. Sci Rep. $2016 ; 6: 30933$. doi:10.1038/srep30933

165. Jetten N, Verbruggen S, Gijbels MJ, Post MJ, De Winther MP, Donners MM. Anti-inflammatory M2, but not pro-inflammatory M1 macrophages promote angiogenesis in vivo. Angiogenesis. 2014;17(1):109-118. doi:10.1007/s10456-013-9381-6

166. Ueta T, Ishihara K, Notomi S, et al. RIP1 kinase mediates angiogenesis by modulating macrophages in experimental neovascularization. Proc Natl Acad Sci U S A. 2019;116(47):23705-23713. doi:10.1073/pnas.1908355116

167. Zhou Y, Yoshida S, Kubo Y, et al. Different distributions of M1 and M2 macrophages in a mouse model of laser-induced choroidal neovascularization. Mol Med Rep. 2017;15(6):3949-3956. doi:10.3892/mmr.2017.6491

168. Xu Y, Cui K, Li J, et al. Melatonin attenuates choroidal neovascularization by regulating macrophage/microglia polarization via inhibition of RhoA/ROCK signaling pathway. J Pineal Res. 2020;69(1):e12660. doi:10.1111/jpi.12660

169. Daftarian N, Zandi S, Piryaie G, et al. Peripheral blood CD163(+) monocytes and soluble CD163 in dry and neovascular age-related macular degeneration. FASEB J. 2020;34(6):8001-8011. doi:10.1096/fj.201901902RR

170. Xu J, Tu Y, Wang Y, et al. Prodrug of epigallocatechin-3-gallate alleviates choroidal neovascularization via down-regulating HIF-1alpha/VEGF/ VEGFR2 pathway and M1 type macrophage/microglia polarization. Biomed Pharmacother. 2020;121:109606. doi:10.1016/j. biopha.2019.109606

171. Ravi R, Ragavachetty Nagaraj N, Subramaniam Rajesh B. Effect of advanced glycation end product on paraoxonase 2 expression: its impact on endoplasmic reticulum stress and inflammation in HUVECs. Life Sci. 2020;246:117397. doi:10.1016/j.lfs.2020.117397

172. Sun Q, Gong L, Qi R, et al. Oxidative stress-induced KLF4 activates inflammatory response through IL17RA and its downstream targets in retinal pigment epithelial cells. Free Radic Biol Med. 2020;147:271-281. doi:10.1016/j.freeradbiomed.2019.12.029

173. Wang K, Zheng M, Lester KL, Han Z. Light-induced Nrf2(-/-) mice as atrophic age-related macular degeneration model and treatment with nanoceria laden injectable hydrogel. Sci Rep. 2019;9(1):14573. doi:10.1038/s41598-019-51151-7

174. Ramchani-Ben Othman K, Cercy C, Amri M, Doly M, Ranchon-Cole I. Dietary supplement enriched in antioxidants and omega-3 protects from progressive light-induced retinal degeneration. PLoS One. 2015;10(6):e0128395. doi:10.1371/journal.pone.0128395

175. Narimatsu T, Ozawa Y, Miyake S, Nagai N, Tsubota K. Angiotensin II type 1 receptor blockade suppresses light-induced neural damage in the mouse retina. Free Radic Biol Med. 2014;71:176-185. doi:10.1016/j.freeradbiomed.2014.03.020 
176. Blasiak J, Piechota M, Pawlowska E, Szatkowska M, Sikora E, Kaarniranta K. Cellular senescence in age-related macular degeneration: can autophagy and DNA damage response play a role? Oxid Med Cell Longev. 2017;2017:5293258. doi:10.1155/2017/5293258

177. Blasiak J. Senescence in the pathogenesis of age-related macular degeneration. Cell Mol Life Sci. 2020;77(5):789-805. doi:10.1007/s00018019-03420-x

178. SanGiovanni JP, Chen J, Sapieha P, et al. DNA sequence variants in PPARGC1A, a gene encoding a coactivator of the omega-3 LCPUFA sensing PPAR-RXR transcription complex, are associated with NV AMD and AMD-associated loci in genes of complement and VEGF signaling pathways. PLoS One. 2013;8(1):e53155. doi:10.1371/journal.pone.0053155

179. Choudhary M, Ding JD, Qi X, et al. PPARbeta/delta selectively regulates phenotypic features of age-related macular degeneration. Aging (Albany NY). 2016;8(9):1952-1978. doi:10.18632/aging.101031

180. Moran E, Ding L, Wang Z, et al. Protective and antioxidant effects of PPARalpha in the ischemic retina. Invest Ophthalmol Vis Sci. 2014;55 (7):4568-4576. doi:10.1167/iovs.13-13127

181. Echeverria F, Ortiz M, Valenzuela R, Videla LA. Long-chain polyunsaturated fatty acids regulation of PPARs, signaling: relationship to tissue development and aging. Prostaglandins Leukot Essent Fatty Acids. 2016;114:28-34. doi:10.1016/j.plefa.2016.10.001

182. Choudhary M, Malek G. A brief discussion on lipid activated nuclear receptors and their potential role in regulating microglia in age-related macular degeneration (AMD). Adv Exp Med Biol. 2016;854:45-51.

183. Pearsall EA, Cheng R, Zhou K, et al. PPAR alpha is essential for retinal lipid metabolism and neuronal survival. BMC Biol. 2017;15(1):113. doi:10.1186/s12915-017-0451-x

184. Bouhlel MA, Derudas B, Rigamonti E, et al. PPARgamma activation primes human monocytes into alternative M2 macrophages with antiinflammatory properties. Cell Metab. 2007;6(2):137-143. doi:10.1016/j.cmet.2007.06.010

185. Fontaine V, Fournie M, Monteiro E, et al. A2E-induced inflammation and angiogenesis in RPE cells in vitro are modulated by PPAR-alpha, -beta/delta, -gamma, and RXR antagonists and by norbixin. Aging (Albany NY). 2021;13(18):22040-22058. doi:10.18632/aging.203558

186. Krezel W, Ruhl R, de Lera AR. Alternative retinoid X receptor (RXR) ligands. Mol Cell Endocrinol. 2019;491:110436. doi:10.1016/j. mce.2019.04.016

187. Sridevi Gurubaran I, Viiri J, Koskela A, et al. Mitophagy in the retinal pigment epithelium of dry age-related macular degeneration investigated in the NFE2L2/PGC-1alpha(-/-) mouse model. Int J Mol Sci. 2020;21(6):1976. doi:10.3390/ijms21061976

188. Zhang M, Chu Y, Mowery J, et al. Pgc-1alpha repression and high-fat diet induce age-related macular degeneration-like phenotypes in mice. Dis Model Mech. 2018;11(9). doi:10.1242/dmm.032698

189. Felszeghy S, Viiri J, Paterno JJ, et al. Loss of NRF-2 and PGC-1alpha genes leads to retinal pigment epithelium damage resembling dry agerelated macular degeneration. Redox Biol. 2019;20:1-12. doi:10.1016/j.redox.2018.09.011

190. Ammar MJ, Hsu J, Chiang A, Ho AC, Regillo CD. Age-related macular degeneration therapy: a review. Curr Opin Ophthalmol. 2020;31 (3):215-221. doi:10.1097/ICU.0000000000000657

191. Wang S, Wang X, Cheng Y, et al. Autophagy dysfunction, cellular senescence, and abnormal immune-inflammatory responses in AMD: from mechanisms to therapeutic potential. Oxid Med Cell Longev. 2019;2019:3632169. doi:10.1155/2019/3632169

192. Yao J, Jia L, Khan N, et al. Deletion of autophagy inducer RB1CC1 results in degeneration of the retinal pigment epithelium. Autophagy. 2015;11(6):939-953. doi:10.1080/15548627.2015.1041699

193. Yumnamcha T, Devi TS, Singh LP. Auranofin mediates mitochondrial dysregulation and inflammatory cell death in human retinal pigment epithelial cells: implications of retinal neurodegenerative diseases. Front Neurosci. 2019;13:1065. doi:10.3389/fnins.2019.01065

194. Su LJ, Zhang JH, Gomez H, et al. Reactive oxygen species-induced lipid peroxidation in apoptosis, autophagy, and ferroptosis. Oxid Med Cell Longev. 2019;2019:5080843. doi:10.1155/2019/5080843

195. Kaarniranta K, Petrovski G, Kauppinen A. The Nobel Prized cellular target autophagy in eye diseases. Acta Ophthalmol. 2017;95(4):335-336. doi:10.1111/aos. 13344

196. Fernandez-Albarral JA, de Julian-lopez E, Soler-Dominguez C, et al. The role of autophagy in eye diseases. Life (Basel). 2021;11(3):189.

197. Yang X, Pan X, Zhao X, et al. Autophagy and age-related eye diseases. Biomed Res Int. 2019;2019:5763658. doi:10.1155/2019/5763658

198. Mitter SK, Song C, Qi X, et al. Dysregulated autophagy in the RPE is associated with increased susceptibility to oxidative stress and AMD. Autophagy. 2014;10(11):1989-2005. doi:10.4161/auto.36184

199. Abokyi S, To CH, Lam TT, Tse DY. Central role of oxidative stress in age-related macular degeneration: evidence from a review of the molecular mechanisms and animal models. Oxid Med Cell Longev. 2020;2020:7901270. doi:10.1155/2020/7901270

200. Roubeix C, Sahel JA, Guillonneau X, Delarasse C, Sennlaub F. [On the inflammatory origins of AMD]. Med Sci (Paris). 2020;36(10):886-892. French. doi: $10.1051 /$ medsci/2020159

201. Saadat KA, Murakami Y, Tan X, et al. Inhibition of autophagy induces retinal pigment epithelial cell damage by the lipofuscin fluorophore A2E. FEBS Open Bio. 2014;4:1007-1014. doi:10.1016/j.fob.2014.11.003

202. Zhang J, Bai Y, Huang L, et al. Protective effect of autophagy on human retinal pigment epithelial cells against lipofuscin fluorophore A2E: implications for age-related macular degeneration. Cell Death Dis. 2015;6:e1972. doi:10.1038/cddis.2015.330

203. Kaarniranta K, Sinha D, Blasiak J, et al. Autophagy and heterophagy dysregulation leads to retinal pigment epithelium dysfunction and development of age-related macular degeneration. Autophagy. 2013;9(7):973-984. doi:10.4161/auto.24546

204. Terluk MR, Kapphahn RJ, Soukup LM, et al. Investigating mitochondria as a target for treating age-related macular degeneration. J Neurosci. 2015;35(18):7304-7311. doi:10.1523/JNEUROSCI.0190-15.2015

205. Nordgaard CL, Karunadharma PP, Feng X, Olsen TW, Ferrington DA. Mitochondrial proteomics of the retinal pigment epithelium at progressive stages of age-related macular degeneration. Invest Ophthalmol Vis Sci. 2008;49(7):2848-2855. doi:10.1167/iovs.07-1352

206. Shimada K, Crother TR, Karlin J, et al. Oxidized mitochondrial DNA activates the NLRP3 inflammasome during apoptosis. Immunity. 2012;36 (3):401-414. doi:10.1016/j.immuni.2012.01.009

207. Bazan NG. Docosanoids and elovanoids from omega-3 fatty acids are pro-homeostatic modulators of inflammatory responses, cell damage and neuroprotection. Mol Aspects Med. 2018;64:18-33. doi:10.1016/j.mam.2018.09.003

208. Bhattacharjee S, Jun B, Belayev L, et al. Elovanoids are a novel class of homeostatic lipid mediators that protect neural cell integrity upon injury. Sci Adv. 2017;3(9):e1700735. doi:10.1126/sciadv.1700735 
209. Do KV, Kautzmann MI, Jun B, et al. Elovanoids counteract oligomeric beta-amyloid-induced gene expression and protect photoreceptors. Proc Natl Acad Sci U S A. 2019;116(48):24317-24325. doi:10.1073/pnas.1912959116

210. Voigt AP, Mulfaul K, Mullin NK, et al. Single-cell transcriptomics of the human retinal pigment epithelium and choroid in health and macular degeneration. Proc Natl Acad Sci U S A. 2019;116(48):24100-24107. doi:10.1073/pnas.1914143116

211. Mau T, Yung R. Adipose tissue inflammation in aging. Exp Gerontol. 2018;105:27-31. doi:10.1016/j.exger.2017.10.014

212. Schnabolk G. Systemic inflammatory disease and AMD comorbidity. Adv Exp Med Biol. 2019;1185:27-31.

213. Opreanu M, Lydic TA, Reid GE, McSorley KM, Esselman WJ, Busik JV. Inhibition of cytokine signaling in human retinal endothelial cells through downregulation of sphingomyelinases by docosahexaenoic acid. Invest Ophthalmol Vis Sci. 2010;51(6):3253-3263. doi:10.1167/ iovs.09-4731

214. Sasaki H, Sueyasu T, Tokuda H, et al. Aging and FADS1 polymorphisms decrease the biosynthetic capacity of long-chain PUFAs: a human trial using [U-(13)C] linoleic acid. Prostaglandins Leukot Essent Fatty Acids. 2019;148:1-8. doi:10.1016/j.plefa.2019.07.003

215. Chataigner M, Mortessagne P, Lucas C, et al. Dietary fish hydrolysate supplementation containing n-3 LC-PUFAs and peptides prevents shortterm memory and stress response deficits in aged mice. Brain Behav Immun. 2021;91:716-730. doi:10.1016/j.bbi.2020.09.022

216. Hadley KB, Bauer J, Milgram NW. The oil-rich alga Schizochytrium sp. as a dietary source of docosahexaenoic acid improves shape discrimination learning associated with visual processing in a canine model of senescence. Prostaglandins Leukot Essent Fatty Acids. 2017;118:10-18. doi:10.1016/j.plefa.2017.01.011

217. Tokuda H, Ito M, Sueyasu T, et al. Effects of combining exercise with long-chain polyunsaturated fatty acid supplementation on cognitive function in the elderly: a randomised controlled trial. Sci Rep. 2020;10(1):12906. doi:10.1038/s41598-020-69560-4

218. Erhardt R, Cardoso BR, Meyer BJ, et al. Omega-3 long-chain polyunsaturated fatty acids: are they beneficial for physical and cognitive functioning in older adults? J Nutr Health Aging. 2021;25(4):454-461. doi:10.1007/s12603-020-1553-7

219. Wang J, Feng Y, Han P, et al. Photosensitization of A2E triggers telomere dysfunction and accelerates retinal pigment epithelium senescence. Cell Death Dis. 2018;9(2):178. doi:10.1038/s41419-017-0200-7

220. Zhong Y, Wang K, Jiang L, et al. Dietary fatty acid intake, plasma fatty acid levels, and the risk of age-related macular degeneration (AMD): a dose-response meta-analysis of prospective cohort studies. Eur J Nutr. 2021;60(6):3013-3027. doi:10.1007/s00394-020-02445-4

Journal of Inflammation Research

\section{Dovepress}

\section{Publish your work in this journal}

The Journal of Inflammation Research is an international, peer-reviewed open-access journal that welcomes laboratory and clinical findings on the molecular basis, cell biology and pharmacology of inflammation including original research, reviews, symposium reports, hypothesis formation and commentaries on: acute/chronic inflammation; mediators of inflammation; cellular processes; molecular mechanisms; pharmacology and novel anti-inflammatory drugs; clinical conditions involving inflammation. The manuscript management system is completely online and includes a very quick and fair peer-review system. Visit http://www.dovepress.com/testimonials.php to read real quotes from published authors.

Submit your manuscript here: https://www.dovepress.com/journal-of-inflammation-research-journal 